Métodos com passo temporal adaptativo para a simulação de escoamentos com superfícies livres

Gabriela Aparecida dos Reis 



\section{Métodos com passo temporal adaptativo para a simulação de escoamentos com superfícies livres}

\section{Gabriela Aparecida dos Reis}

Orientador: Prof. Dr. José Alberto Cuminato

Dissertação apresentada ao Instituto de Ciências Matemáticas e de Computação - ICMC-USP, como parte dos requisitos para obtenção do título de Mestre em Ciências - Ciências de Computação e Matemática Computacional. VERSÃO REVISADA

USP - São Carlos

Junho de 2012 
Ficha catalográfica elaborada pela Biblioteca Prof. Achille Bassi e Seção Técnica de Informática, ICMC/USP, com os dados fornecidos pelo(a) autor(a)

\begin{tabular}{|c|c|}
\hline \multirow[t]{3}{*}{ A $375 \mathrm{~m}$} & $\begin{array}{l}\text { Aparecida dos Reis, Gabriela } \\
\text { Métodos com passo temporal adaptativo para a } \\
\text { simulação de escoamentos com superfícies livres / } \\
\text { Gabriela Aparecida dos Reis; orientador José Alberto } \\
\text { Cuminato. -- São Carlos, } 2012 \text {. } \\
\quad 55 \text { p. }\end{array}$ \\
\hline & $\begin{array}{l}\text { Dissertação (Mestrado - Programa de Pós-Graduação em } \\
\text { Ciências de Computação e Matemática Computacional) -- } \\
\text { Instituto de Ciências Matemáticas e de Computação, } \\
\text { Universidade de São Paulo, } 2012 \text {. }\end{array}$ \\
\hline & $\begin{array}{l}\text { 1. Mecânica dos fluidos computacional. I. Alberto } \\
\text { Cuminato, José, orient. II. Título. }\end{array}$ \\
\hline
\end{tabular}


"Sempre me pareceu estranho que todos aqueles que estudam seriamente esta ciência acabam tomados de uma espécie de paixão pela mesma. Em verdade, o que proporciona o máximo de prazer não é o conhecimento e sim a aprendizagem, não é a posse, mas a aquisição, não é a presença, mas o ato de atingir a meta." - CARL Friedrich GAUSS 


\section{Agradecimentos}

Agradeço a Deus pelo dom da vida e por iluminar meus passos na conclusão de mais uma etapa.

A Sebastião dos Reis Pinto, meu pai, Marcos Vinícius de Freitas Reis, meu irmão, pelo amor, paciência, compreensão e incentivo durante os meus estudos. À Anerli de Fátima Freitas dos Reis, minha mãe, que mesmo hoje não estando entre nós, ainda posso sentir sua energia positiva me incentivando a sempre buscar meus ideais.

À toda minha família que sempre torceu por mim pedindo a Deus para guiar meus passos.

A Italo Tasso, meu namorado, pelo carinho, paciência e dedicação em me ajudar a finalizar este trabalho.

A José Alberto Cuminato, meu orientador, pela paciência, disponibilidade, apoio e, principalmente, pelos ensinamentos e orientações.

A Alessandro Alves Santana, meu orientador de iniciação científica, pelos seus ensinamentos e apoio.

À Juliana Bertoco, minha amiga, por toda ajuda, paciência, carinho e incetivo em nunca desistir.

À Valéria de Carvalho Santos, minha companheira de república, pela confiança depositada, companheirismo e amizade conquistada nesse tempo.

Aos amigos do Grupo de Oração Universitário pela força espiritual, pelos bons momentos.

Aos colegas, funcionários e professores do ICMC/USP pela convivência.

A todos professores da Faculdade de Matemática da Universidade Federal de Uberlândia que contribuíram para a minha formação inicial, em especial, Marcos Antônio da Câmera, tutor do PET, pela força e amizade.

À FAPESP e ao CNPq pelo apoio financeiro concedido na realização do meu projeto de pesquisa.

Seriam muitas pessoas a agradecer, citar todas seria impossível, mas em meu coração todas são lembradas, meu muito obrigada. 


\section{Resumo}

A simulação de escoamentos com superfícies livres vem ganhando importância ao longo dos últimos anos devido às várias aplicações práticas em que esse tipo de escoamento está envolvido. Dentre os métodos numéricos existentes para a simulação de escoamentos, temos o GENSMAC, que é uma técnica numérica para simular escoamentos newtonianos com superfícies livres. A implementação de métodos semi-implícitos para a discretização temporal das equações de Navier-Stokes permitiu uma relaxação significativa na restrição no passo temporal, reduzindo consideravelmente o custo computacional na simulação de escoamentos com $R e \ll 1$. Mas, mesmo no caso dos métodos semi-implícitos, o passo temporal não pode aumentar além de certos limites, bem aquém daquele da restrição $C F L$, sem provocar sérios problemas de precisão nos resultados numéricos e consequente aparecimento de resultados não físicos. Portanto, mesmo na formulação semi-implícita, uma restrição no passo temporal é aplicada. Neste trabalho, analisamos e implementamos no sistema FREEFLOW2D uma estratégia de adaptação do passo temporal de maneira a garantir a estabilidade e a precisão utilizando o maior passo temporal possível. A eficiência e robustez da técnica incorporada à formulação implícita do GENSMAC são demonstradas na solução de problemas bidimensionais complexos com superfícies livres e baixo número de Reynolds, incluindo os problemas do inchamento do extrudado e jet flow.

Palavras-chave: métodos numéricos, superfícies livres, passo temporal adaptativo. 


\section{Abstract}

The simulation of free surfaces flows has gained importance in the recent years due to the many practical applications of this type of flow. Among the many numerical methods available for the simulation of fluid flows, there is GENSMAC, which is a numerical technique to simulate Newtonian flows with free surfaces. The implementation of semi-implicit methods for the temporal discretization of the Navier-Stokes equations allowed a significant loosening in the time step restriction, reducing considerably the computational cost of the simulation of flows with $R e \ll 1$. But, even with the semi-implicit methods, the time step cannot increase beyond certain limits, well below the $C F L$ restriction, without causing serious accuracy problems in the numerical results and the consequent appearance of non-physical results. Therefore, even in the semi-implicit formulation, a time step restriction is applied. In this work, we analyse and implement in the FREEFLOW2D system a strategy for adaptive time-stepping in order to ensure stability and precision while using the largest possible time step. The efficiency and robustness of the technique incorporated to the implicit formulation of GENSMAC are demonstrated in the solution of two-dimensional complex problems with free surfaces and low Reynolds numbers, including the swelling of the extrudate and jet flow problems.

Key-words: numerical methods, free surfaces, adaptive time-stepping. 


\section{Sumário}

1 Introdução $\quad 1$

2 Formulação Matemática $\quad 5$

2.1 Introdução . . . . . . . . . . . . . . . . . . . . 5

2.2 Equações governantes . . . . . . . . . . . . . . . . . . 6

2.3 Adimensionalização das equações . . . . . . . . . . . . . . . . . 7

2.4 Condições auxiliares . . . . . . . . . . . . . . . . . . . . 8

2.4 .1 Contorno rígido . . . . . . . . . . . . . . . 8

2.4.2 Fronteira de entrada de fluido (inflow) . . . . . . . . . . . . . 9

2.4.3 Fronteira de saída de fluido (outflow) . . . . . . . . . . . . . . . 9

2.4 .4 Superfície livre . . . . . . . . . . . . . . . . . . . . . 9 9

3 A metodologia GENSMAC $\quad 11$

3.1 Introdução . . . . . . . . . . . . . . . . . . . . . . . . 11

3.2 Método de projeção . . . . . . . . . . . . . . . . . . . 14

3.3 Formulação implícita do GENSMAC . . . . . . . . . . . . . . . . . . 15

3.4 Algoritmo Computacional . . . . . . . . . . . . . . . . . . 16

3.5 Cálculo do passo de tempo . . . . . . . . . . . . . . . . 18

4 GENSMAC com Passo Temporal Adaptativo $\quad 21$

4.1 Introdução . . . . . . . . . . . . . . . . . . . . . . . . . 21

4.2 Método com Passo Temporal Adaptativo . . . . . . . . . . . . . . . . . 22

4.2 .1 Integração no tempo . . . . . . . . . . . . . . . . . 22

4.2.2 Método de seleção do passo de tempo . . . . . . . . . . . . . . . . . 26

5 Resultados $\quad 31$

5.1 Introdução . . . . . . . . . . . . . . . . . . . 31

5.2 Verificação do método numérico . . . . . . . . . . . . . . . . . 32 
5.2.1 Contração planar $4: 1 \ldots \ldots \ldots \ldots \ldots$. . . . . . . . . . . . . . 32

5.2 .2 Poiseuille flow e Fountain flow . . . . . . . . . . . . . . . 36

5.3 Aplicações . . . . . . . . . . . . . . . . . . . . . . . 40

5.3.1 Inchamento do extrudado . . . . . . . . . . . . . . . . 40

5.3 .2 Jet flow . . . . . . . . . . . . . . . . . . . . 46

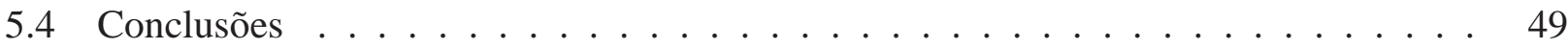

6 Considerações Finais $\quad 51$

$\begin{array}{ll}\text { Referências Bibliográficas } & 53\end{array}$ 


\section{Lista de Figuras}

3.1 Representação da célula $C_{i, j}$, tipo MAC, em $t=t_{n}$ : as velocidades $u$ e $v$ nas faces e a pressão (representada pela variável $\phi$ ), no centro da célula. . . . . . . . . . . . .

3.2 Classificação das células do domínio computacional (a) para a simulação do escoamento representado em (b), extraído de [TM99] . . . . . . . . . . . . . . . . . . . 13

3.3 Aproximações da superfície livre em célula $\mathbf{S}$ : casos de $90^{\circ} \ldots \ldots \ldots \ldots$. . . . . . . . 14

3.4 Aproximações da superfície livre em célula $\mathbf{S}$ : casos de $45^{\circ} \ldots \ldots \ldots \ldots$

5.1 Ilustração do domínio para simulação da contração planar $4: 1 \ldots$. . . . . . . . . 33

5.2 Valores do passo temporal usados para a simulação da contração planar $4: 1$, con-

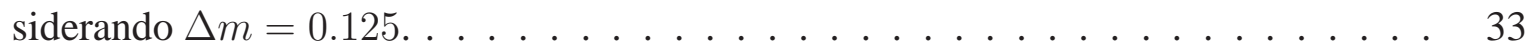

5.3 Comparação entre o valor do erro $\left\|\mathrm{e}^{n}\right\|$ para o passo temporal adaptativo e dois casos com passo fixo obtidos na simulação da contração planar $4: 1$. . . . . . . . . . . 34

5.4 Evolução da contração planar $4: 1(R e=0.05)$ utilizando o passo temporal adaptativo. Na figura estão representados os resultados numéricos para pressão, perfil de velocidade em $x$ e $y$, respectivamente. Em $t \approx 3.365 \times 10^{-1}$ o fluido atinge o estado estacionário. . . . . . . . . . . . . . . . . . . .

5.5 Ilustração do domínio para simulação do poiseuille flow. Coloca-se outflow nas duas extremidades para representar a condição de Neumann no contorno. . . . . . . . . . 36

5.6 Comparação entre a solução exata $\square$ e a solução numérica * para o escoamento poiseuille flow em diferentes tempos usando o passo temporal adaptativo, no ponto

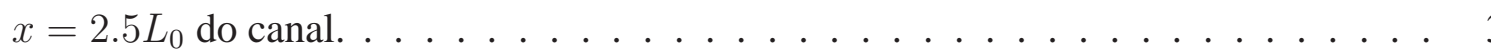

5.7 Ilustração do domínio para simulação do foutain flow . . . . . . . . . . . . . . . 38

5.8 Valores do passo temporal usados na simulação do fountain flow, considerando $\Delta m=$ 0.025. Em laranja, a curva do passo temporal adaptativo foi suavizada tomando-se a média dos 500 pontos vizinhos. . . . . . . . . . . . . . . . . . . 
5.9 Comparação entre o valor do erro $\left\|\mathbf{e}^{n}\right\|$ para o passo temporal adaptativo e dois casos com passo fixo obtidos na simulação do Fountain Flow. As curvas foram suavizadas tomando-se a média dos 500 pontos vizinhos. . . . . . . . . . . . . . . .

5.10 Evolução do fountain flow (Re $=0.1$ ) utilizando o passo temporal adaptativo. Na figura estão representados os resultados numéricos para pressão, perfil de velocidade em $x$ e $y$, respectivamente. Em $t \approx 7.0$ o fluido chega ao outflow e em $t \approx 11.64$ atinge o estado estacionário. . . . . . . . . . . . . . . 4

5.11 Ilustração do domínio para simulação do inchamento do extrudado. . . . . . . . . . . 43

5.12 Valores do passo temporal usados na simulação do inchamento do extrudado, considerando $\Delta m=0.025$. Em laranja, a curva do passo temporal adaptativo foi suavizada tomando-se a média dos 500 pontos vizinhos. . . . . . . . . . . . . .

5.13 Comparação entre o valor do erro $\left\|\mathrm{e}^{n}\right\|$ para o passo temporal adaptativo e dois casos com passo fixo obtidos na simulação do inchamento do extrudado. As curvas foram suavizadas tomando-se a média dos 500 pontos vizinhos. . . . . . . . . . . . .

5.14 Evolução do inchamento do extrudado $(R e=0.1)$ utilizando o passo temporal adaptativo. Na figura estão representados os resultados numéricos para pressão, perfil de velocidade em $x$ e $y$, respectivamente. Em $t \approx 4.5$ o fluido sai do canal, chegando no outflow em $t \approx 16.0$ e em $t \approx 33.0$ atinge o estado estacionário. . . . . . . . . . . .

5.15 Ilustração do domínio para simulação do jet flow. . . . . . . . . . . . . . . . . .

5.16 Valores do passo temporal usados na simulação do jet flow, considerando $\Delta m=$ 0.125. Em laranja, a curva do passo temporal adaptativo foi suavizada tomando-se a média dos 500 pontos vizinhos. . . . . . . . . . . . . . . . . .

5.17 Comparação entre o valor do erro $\left\|\mathrm{e}^{n}\right\|$ para o passo temporal adaptativo e dois casos com passo fixo obtidos na simulação do jet flow. As curvas foram suavizadas tomando-se a média dos 500 pontos vizinhos.

5.18 Solução numérica do jet flow $(R e=0.2)$ utilizando o passo temporal adaptativo em $t=80.0$. Na figura estão representados os resultados numéricos para pressão, perfil de velocidade em $x$ e $y$, respectivamente. . . . . . . . . . . . . . . 


\section{Lista de Tabelas}

5.1 Tempo de processamento para a simulação da contração planar $4: 1$ até $t=1.0 \ldots$. . 34

5.2 Tempo de processamento para a simulação do fountain flow até $t=20.0 \ldots$. . . . 40

5.3 Valores para a solução numérica $\mathbf{u}^{n}$, a solução exata $u(x, y, t)$ e o |erro| no ponto

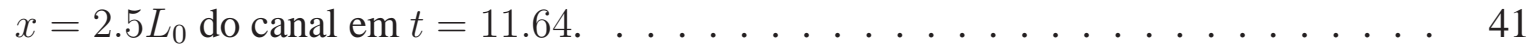

5.4 Tempo de processamento para a simulação do inchamento do extrudado até $t=45.0 . \quad 44$

5.5 Tempo de processamento para a simulação do jet flow até $t=80.0 \ldots \ldots$. . . . . 48 


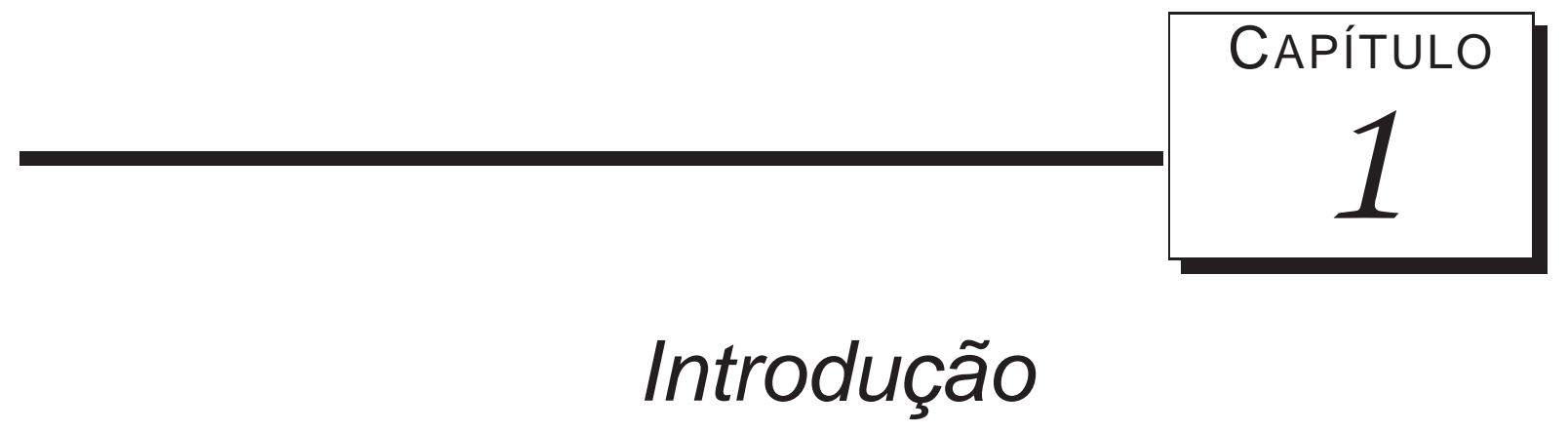

A Dinâmica dos Fluidos Computacional tem atraído diversos pesquisadores de diversas áreas de aplicação ao estudo e desenvolvimento de métodos numéricos para obtenção de soluções para as equações governantes de fenômenos físicos em Mecânica dos Fluidos Computacional (MFC). Um dos problemas mais importantes é a simulação de escoamentos com superfícies livres. O motivo desse interesse se deve ao fato de que existe uma grande gama de aplicações para as quais o estudo destes escoamentos é importante, como por exemplo na agitação de fluidos em recipientes vibrantes, em escoamentos de marés em baías, entre outros problemas. Escoamentos de fluidos com a presença de superfícies livres apresentam dificuldades que merecem uma atenção especial, pois além de resolver as equações governantes, a superfície livre precisa ser determinada ao mesmo tempo, o que adiciona uma dificuldade computacional.

Dentre os métodos numéricos utilizados para tratar escoamentos de fluidos com superfícies livres, o método de diferenças finitas parece ser bastante adequado. Assim, a primeira tentativa bem sucedida de desenvolvimento de uma metodologia numérica para a simulação de escoamentos (newtonianos) incompressíveis com superfícies livres, via variáveis primitivas (pressão e velocidade), surge com o método MAC (Marker-And-Cell) em [HW65]. Neste método o fluido é representado utilizando-se partículas virtuais.

Uma simplificação do método MAC se dá em [AH70], que apresenta o SMAC (Simplified MarkerAnd-Cell) influenciado pelas idéias dos métodos de projeção ([CH67], [CH68]), onde os ciclos de cálculo são divididos em velocidade e pressão, eliminando as dificuldades encontradas no método MAC.

Com [TM93] e [TM94] surge o GENSMAC (GENeralized Simplified Marker-And-Cell), que é uma técnica numérica para simular escoamentos newtonianos com superfícies livres em domínios bidimensionais com geometria complexa, permitindo a utilização de várias entradas e saídas de fluido 
e contornos rígidos curvos. Além disso, o GENSMAC passa a empregar partículas virtuais para representar apenas a superfície livre do fluido, proporcionando uma significativa redução no uso de memória e no custo computacional.

O GENSMAC, em sua formulação inicial ([TM94]), é um método explícito tanto para a integração temporal da equação de conservação do momento quanto para a aproximação da condição de contorno para a pressão na superfície livre, constituindo a Formulação Explícita (FE) do GENSMAC. Metodologias explícitas para a solução numérica das equações governantes apresentam restrição de estabilidade muito severas para a definição do passo temporal, acarretando um custo computacional relativamente alto. Essa restrição é calculada de acordo com o parâmetro adimensional número de Reynolds e o espaçamento da malha. Consequentemente, escoamentos de fluidos com $R e \ll 1$ requerem muitos passos no tempo e portanto gastam muito tempo de processamento. Para eliminar a restrição de estabilidade parabólica e diminuir o custo computacional, em [OC04] foram desenvolvidos e implementados métodos semi-implícitos para aproximar a equação de conservação da quantidade de movimento e a pressão na superfície livre, constituindo a Formulação Implícita (FI) do GENSMAC. Conseguiu-se assim uma relaxação significativa da restrição no passo temporal, permitindo reduzir consideravelmente o custo computacional na simulação de escoamentos em que $R e \ll 1$. Mas, mesmo no caso dos métodos semi-implícitos, o passo temporal não pode aumentar além de certos limites, bem aquém daquele da restrição $C F L$, sem provocar sérios problemas de precisão nos resultados numéricos e consequente aparecimento de resultados não físicos. Portanto, mesmo na formulação semi-implícita uma restrição no passo temporal é imposta, por meio de fatores empíricos.

Uma ferramenta para eliminar tal restrição é usar métodos com passo temporal adaptativo. Várias estratégias de escolha do passo de tempo vêm sendo desenvolvidos para resolução de equações diferenciais parciais com o objetivo de proporcionar, de maneira mais eficiente soluções que sejam estáveis e precisas. Em geral, esses algoritmos usam aproximações dos erros de truncamento locais na escolha do novo passo de tempo. Em [GS00A] e [GS00B] os esquemas sugeridos usam um método do tipo previsor-corretor com estimativas para o erro de truncamento local na seleção do passo de tempo. Dentre eles, destaca-se a Regra dos Trapézios com passo de tempo variável ou integrador inteligente, que utiliza como corretor o método implícito Crank-Nicolson e como previsor o método explícito de Adams-Bashforth. Por volta de 1960, Fehlberg propôs os métodos de Runge-Kutta embutidos. Tais métodos utilizam dois esquemas de Runge-Kutta de ordens diferentes ( $p$ e $p-1)$ de tal forma que a diferença entre as aproximações produz uma estimativa do erro local, que é então utilizada como função de ajuste do passo temporal ([HN00]). Alguns métodos utilizados para a adaptabilidade temporal são: Runge-Kutta Fehlberg (F23) e (F45).

Neste contexto, com base nos trabalhos de [GP08] e [KD10], que formularam uma versão refinada do integrador inteligente de [GS00A] e [GS00B], o presente trabalho pretende incorporar à FI do GENSMAC, o método com passo temporal adaptativo. E assim, pretendemos minimizar o esforço computacional desse método, para obter uma precisão fixada, isto é, oferecer um meio de resolver 
problemas de escoamentos complexos com custo otimizado e controle da precisão das simulações numéricas.

Todos os resultados produzidos neste trabalho foram implementados no Sistema FREEFLOW2D ([OL99], [CF00]), que consiste de um pacote computacional desenvolvido pelo grupo de MFC do Laboratório de Matemática Aplicada e Matemática Computacional (LMACC) do ICMC-USP. Este software está implementado em linguagem C sob o sistema operacional LINUX, possui três módulos: modelador, simulador e visualizador, que permitem, respectivamente, a modelagem, a simulação e a visualização de escoamentos transientes e incompressíveis com superfície livre.

O restante do texto é organizado como segue. Os capítulos 2 e 3 constituem no levantamento bibliográfico. No primeiro deles, são apresentadas as equações que modelam o escoamento de um fluido newtoniano, bem como as condições auxiliares que devem ser impostas em cada circunstância física. Já no Capítulo 3, são esboçadas as principais idéias que constituem o GENSMAC como um método de projeção (baseado no Teorema da Decomposição de Helmholtz-Hodge). Apresentamos de forma reduzida, o algoritmo da formulação implícita do GENSMAC. Nos capítulos que seguem, 4 e 5, são apresentados, respectivamente, a formulação matemática utilizada para o método com passo temporal adaptativo e os resultados que demonstram a eficiência da implementação desta técnica no GENSMAC.

Por fim, no Capítulo 6, as considerações finais são apresentadas incluindo os possíveis trabalhos futuros que darão continuidade a este projeto. 


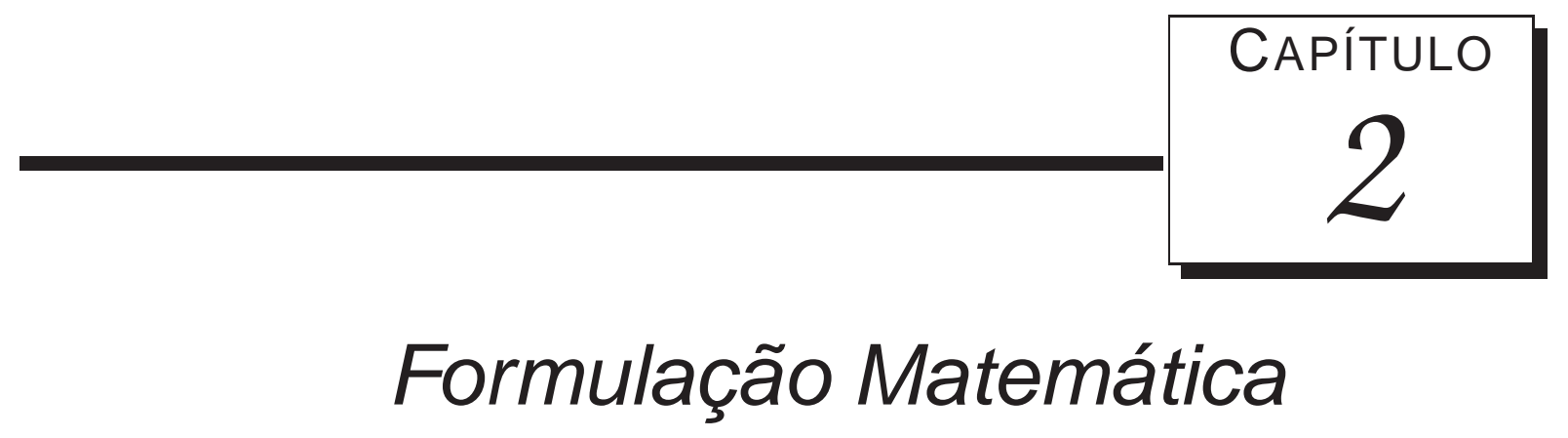

\subsection{Introdução}

O mundo como hoje o conhecemos, no que tange ao conforto tecnológico tem grande contribuição da matemática. Esta é uma ferramenta fundamental no estudo qualitativo e quantitativo de processos naturais. Permite estudar com minúcias fenômenos físicos que aparecem nas modelagens matemáticas dos referidos fenômenos. Fornece o embasamento para tomadas de decisões em vários campos do conhecimento, principalmente o campo tecnológico, dando diretrizes para a criação, desenvolvimento e aprimoramento de novas tecnologias. Consequentemente, a modelagem matemática ganhou grande espaço pois a análise detalhada de um modelo e suas propriedades juntamente com o avanço da computação científica e dos computadores, permitem que um conjunto de Equações Diferencias Parciais (EDPs), definidas em um domínio com geometria complexa, sejam avaliadas e reavaliadas sem a necessidade de experimentação prática. Isso proporciona economia de tempo e diminuição de custos. E, devido à limitação das técnicas analíticas, tem sido dado grande ênfase ao desenvolvimento de métodos de resolução numérica de EDPs em várias instituições científicas pelo mundo.

O foco deste trabalho é a Mecânica dos Fluidos Computacional (MFC) e, de forma mais específica a simulação numérica de escoamentos incompressíveis e isotérmicos que são modelados pelas equações de Navier-Stokes, além de um conjunto de condições auxiliares fisicamente plausíveis que definem o que ocorre no limiar da região de definição espacial e temporal do escoamento.

Os fluidos em estudo, newtonianos, são classificados como aqueles com taxa de deformação proporcional à tensão de cisalhamento, sendo a constante de proporcionalidade a viscosidade dinâmica do fluido. Existem outros fluidos para os quais a relação de proporcionalidade não é satisfeita, o que caracteriza os fluidos não-newtonianos.

No restante do capítulo, são apresentadas as equações que modelam o escoamento de um fluido 
newtoniano, bem como as condições auxiliares que devem ser impostas às mesmas nas situações de interesse.

\subsection{Equações governantes}

Escoamentos transientes e incompressíveis são modelados pelas equações de Navier-Stokes. Tais equações traduzem, para a linguagem matemática, os princípios físicos de conservação de massa, de momento e de energia. Neste trabalho, serão considerados escoamentos incompressíveis e isotérmicos, consequentemente variações de densidade e de temperatura serão ignoradas. Isto nos permite eliminar o princípio de conservação de energia, de forma que abordamos apenas os princípios de conservação de massa e de momento.

Considerando um sistema de coordenadas cartesianas $2 \mathrm{D}$, seja $\mathbf{x}=\left[\begin{array}{l}x \\ y\end{array}\right]$ o vetor posição e $\mathbf{u}=\left[\begin{array}{l}u \\ v\end{array}\right]$ o vetor velocidade, com $\mathbf{u}=\mathbf{u}(\mathbf{x}, t)$ no instante de tempo $t \geqslant 0$. Seja, também, $\mathbf{g}=\mathbf{g}(\mathbf{x}, t)$, o campo gravitacional e $\tau=\left[\begin{array}{cc}\tau^{x x} & \tau^{x y} \\ \tau^{y x} & \tau^{y y}\end{array}\right], \tau=\tau(\mathbf{x}, t)$, o tensor tensão extra, que é simétrico ([BH87]), com $p=p(\mathbf{x}, t)$ a pressão. Assim, definimos o tensor tensão total $\sigma=\sigma(\mathbf{x}, t)$ por

$$
\sigma=\tau-p \mathbf{I}=\left[\begin{array}{cc}
\tau^{x x}-p & \tau^{x y} \\
\tau^{x y} & \tau^{y y}-p
\end{array}\right]
$$

onde I é o tensor identidade.

Portanto, as equações de conservação do momento e da massa são dadas na forma vetorial, respectivamente, por

$$
\begin{aligned}
\frac{\partial \mathbf{u}}{\partial t}+\nabla \cdot(\mathbf{u u}) & =\nabla \cdot \sigma+\frac{1}{F r^{2}} \mathbf{g} \\
\nabla \cdot \mathbf{u} & =0
\end{aligned}
$$

onde $\mathrm{Fr}$ é o número adimensional de Froude.

Para determinar o tensor de tensão extra, utilizamos a equação constitutiva do fluido. Supondo (2.3), a equação constitutiva para um fluido newtoniano é dada por

$$
\tau=\frac{2}{R e} D
$$

onde $R e$ é o número adimensional de Reynolds e, $D$ o tensor taxa de deformação, dado por

$$
D=\frac{1}{2}\left(\nabla \mathbf{u}+(\nabla \mathbf{u})^{T}\right),
$$

sendo $\nabla \mathbf{u}$ o tensor gradiente de velocidade e $(\nabla \mathbf{u})^{T}$ seu transposto. 
Substituindo (2.4) nas equações (2.2) e (2.3), segue as equações de Navier-Stokes para o escoamento incompressível e isotérmico de um fluido newtoniano,

$$
\begin{aligned}
\frac{\partial \mathbf{u}}{\partial t}+\nabla \cdot(\mathbf{u u}) & =-\nabla p+\frac{1}{R e} \nabla^{2} \mathbf{u}+\frac{1}{F r^{2}} \mathbf{g} \\
\nabla \cdot \mathbf{u} & =0 .
\end{aligned}
$$

\subsection{Adimensionalização das equações}

Uma estratégia para melhor compreensão das variáveis significativas do problema é a adimensionalização das equações que descrevem o modelo. Sendo assim, todas as equações utilizadas nesta seção estão em sua forma adimensional, assim como suas variáveis e parâmetros. As escalas normalmente adotadas para caracterizar um escoamento são $L_{0}, U_{0}, \mu_{0}, \rho_{0}, g_{0}$ representando, respectivamente, o comprimento, a velocidade, a viscosidade dinâmica, a densidade e o campo gravitacional. Assim, introduzimos as variáveis adimensionais relacionadas com as respectivas variáveis dimensionais (acrescidas do índice *):

$$
\mathbf{x}=\frac{\mathbf{x}^{*}}{L_{0}}, \quad \mathbf{u}=\frac{\mathbf{u}^{*}}{U_{0}}, \quad t=\frac{U_{0}}{L_{0}} t^{*}, \quad \mathbf{g}=\frac{\mathbf{g}^{*}}{g_{0}}, \quad p=\frac{p^{*}}{\rho_{0} U_{0}^{2}}, \quad \tau=\frac{\tau^{*}}{\rho_{0} U_{0}^{2}} .
$$

Dentre os parâmetros adimensionais, apresentamos os que são importantes para o modelo newtoniano, como pode ser observado nas equações (2.6) e (2.7):

- Número de Reynolds (Re): Dado por

$$
R e=\frac{\rho_{0} L_{0} U_{0}}{\mu_{0}}=\frac{L_{0} U_{0}}{\nu}
$$

fornece a razão entre as forças inerciais e as forças viscosas ou difusivas que operam no escoamento e $\nu$ é a viscosidade cinemática.

- Número de Froude (Fr): Dado por

$$
F r=\frac{U_{0}}{\sqrt{g_{0} L_{0}}}
$$

estabelece a razão entre as forças inerciais e as forças de campo, ou seja, caracteriza escoamentos em que o campo gravitacional tem papel importante, como é o caso de escoamentos com superfície livre. 


\subsection{Condições auxiliares}

O sistema de equações que modela o escoamento de um fluido é um sistema de EDPs. Por isso, em geral apresenta uma família infinita de soluções. No entanto, do ponto de vista físico é razoável esperar que esse sistema de equações apresente uma solução única. Para que isso se faça possível, condições sobre a evolução do escoamento no tempo e no espaço são necessárias para caracterizar melhor a situação modelada. Estas condições são:

- Condições iniciais - Fornecem os dados que o problema modelado assume em seu estado inicial, informando a partir de onde e com qual valor a solução vai se propagar. O campo de velocidade inicial $\mathbf{u}_{0}$ deve satisfazer o estado de equilíbrio imposto pela equação da continuidade enquanto que a pressão precisa ser escolhida de forma compatível com o campo de velocidade, geralmente, no tempo inicial $t_{0}$ é considerada nula ([FT00]).

- Condições de fronteira - Fornecem as condições que o problema modelado assume no contorno da região de definição do problema, isto é, informam sobre as situações físicas da solução na fronteira espacial da região onde ela existe.

Nas subseções seguintes serão apresentadas as condições auxiliares utilizadas neste trabalho.

\subsubsection{Contorno rígido}

É aquele que não permite fluxo de massa em sua direção normal. Assim, sendo $\mathbf{u}_{\vec{n}}$ a componente normal da velocidade na fronteira, deve satisfazer:

$$
\mathbf{u}_{\vec{n}}=0 .
$$

Quanto à velocidade tangencial $\mathbf{u}_{\vec{t}}$ ao longo da fronteira, podemos ter dois casos:

- Condição de não aderência (free-slip) - Esta condição permite que o fluido deslize livremente sobre a superfície sólida sem atrito, é também aplicada em problemas onde há um plano de simetria. Logo, é conveniente impor que a taxa de variação da componente da velocidade paralela à fronteira seja nula ao longo da direção $\vec{n}$, isto é,

$$
\frac{\partial \mathbf{u}_{t}}{\partial \vec{n}}=0
$$

Esta condição não foi utilizada neste trabalho.

- Condição de aderência completa (no-slip) - Esta condição considera que o fluido imediatamente adjacente à superfície sólida deve estar em repouso em relação à mesma. Assim,

$$
\mathbf{u}_{\vec{t}}=u_{f}
$$


onde $u_{f}$ é a velocidade da fronteira. Quando a fronteira está em repouso,

$$
u_{f}=0
$$

\subsubsection{Fronteira de entrada de fluido (inflow)}

Por este tipo de fronteira se dá a entrada de fluido no domínio onde ocorre o escoamento. As componentes $\mathbf{u}_{\vec{n}}$ e $\mathbf{u}_{\vec{t}}$ da velocidade, respectivamente, normal e tangencial a essa fronteira devem ser tais que

$$
\begin{aligned}
& \mathbf{u}_{\vec{n}}=u_{\text {inflow }} \\
& \mathbf{u}_{\vec{t}}=0
\end{aligned}
$$

onde $u_{\text {inflow }}$ é a velocidade de entrada do fluido no domínio.

\subsubsection{Fronteira de saída de fluido (outflow)}

Por este tipo de fronteira se dá a saída de fluido do domínio onde ocorre o escoamento na qual o fluido sai de forma espontânea. Deve ser imposta a condição de Neumann homogênea para a velocidade, isto é,

$$
\begin{aligned}
& \frac{\partial \mathbf{u}_{\vec{t}}}{\partial \vec{n}}=0, \\
& \frac{\partial \mathbf{u}_{\vec{n}}}{\partial \vec{n}}=0 .
\end{aligned}
$$

\subsubsection{Superfície livre}

Escoamentos com superfícies livres são uma classe especial de escoamentos com fronteiras móveis. Com isso, a posição do contorno é conhecida apenas no tempo inicial, e sua localização nos próximos tempos deve ser determinada como parte da solução. Consequentemente condições de contorno na superfície livre devem ser impostas.

A superfície livre representa uma interface entre a superfície de contato do fluido com a atmosfera. Esta condição exige que as forças que atuam sobre o fluido na superfície livre estejam em equilíbrio (conservação do momento na superfície livre).

Supondo uma atmosfera externa passiva, a resultante das forças na superfície livre é nula. Assim, devemos impor que a componente do tensor tensão total $\sigma$ ao longo da superfície livre também seja nula. Segue de (2.1) que a componente de $\sigma$ ao longo da superfície livre é dada pelo vetor $\sigma \cdot \vec{n} ; \operatorname{logo}$, devemos impor que as componentes, normal e tangencial se anulem, isto é, 


$$
\begin{aligned}
& \vec{n} \cdot(\sigma \cdot \vec{n})=0, \\
& \vec{t} \cdot(\sigma \cdot \vec{n})=0,
\end{aligned}
$$

onde

$$
\vec{n}=\left[\begin{array}{l}
n_{x} \\
n_{y}
\end{array}\right], \vec{t}=\left[\begin{array}{c}
n_{y} \\
-n_{x}
\end{array}\right]
$$

são os versores normal e tangencial, respectivamente, ao longo da superfície livre do fluido. 
CAPÍTULO

3

\section{A metodologia GENSMAC}

\subsection{Introdução}

A primeira metodologia numérica para a simulação de escoamentos newtonianos incompressíveis, surge com o método de partículas marcadoras, Marker and Cell (MAC) em [HW65], que originalmente foi desenvolvido para resolver problemas com superfícies livres. Tal método motivou vários outros, dentre os quais pode-se destacar o Simplified Marker and Cell (SMAC) de [AH70], utilizado para eliminar as dificuldades associadas com a aplicação das condições de fronteira do MAC. Estendendo a aplicabilidade do SMAC para o tratamento de domínios 2D arbitrários, surge com [TM93] o GENeralized Simplified Marker-And-Cell (GENSMAC). Neste, uma sequência de partículas marcadoras (formando uma poligonal orientada) constitui a aproximação numérica para a superfície livre do fluido. Esta estratégia economiza memória e tempo de processamento nas simulações numéricas. Usando essas partículas, a superfície livre é aproximada por uma superfície linear e representada por uma estrutura de dados chamada half edge, este tipo de estrutura representa os objetos geométricos por suas faces, arestas, vértices e relações topológicas ([MM88]).

Desta forma, utiliza-se uma malha fixa (euleriana) que é composta por células, onde as equações são discretizadas por diferenças finitas de maneira deslocada (staggered grid), com espaçamento uniforme:

$$
\Delta m=\Delta x=\Delta y
$$

Nesta malha, como pode ser observado na Figura 3.1, as velocidades são definidas nas faces da célula enquanto as demais grandezas como a pressão (representada pela variável $\phi$ ), são avaliadas em seu centro. A superfície livre é representada por uma malha móvel (lagrangeana) e é movimentada de acordo com o campo de velocidade calculado. A movimentação da superfície livre é determinada 
pela convecção das partículas, resolvendo a equação

$$
\frac{d \mathbf{x}}{d t}=\mathbf{u}(\mathbf{x}, t)
$$

para cada partícula, sendo $\mathrm{x}$ a posição da partícula na malha fixa.

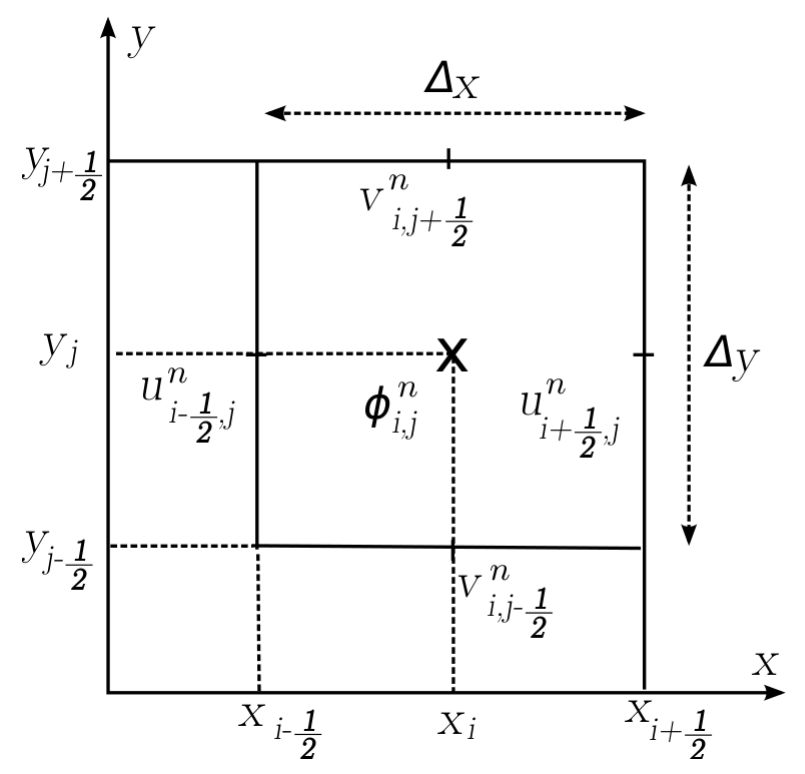

Figura 3.1: Representação da célula $C_{i, j}$, tipo MAC, em $t=t_{n}$ : as velocidades $u$ e $v$ nas faces e a pressão (representada pela variável $\phi$ ), no centro da célula.

As propriedades do escoamento são representadas em uma malha de células retangulares classificadas conforme ilustra a Figura 3.2, para tornar a ilustração mais clara, as células em branco são células vazias. Assim, temos:

- Células vazias (E: empty) - são aquelas que não possuem fluido em seu interior.

- Células cheias (F: full) - possuem fluido em seu interior; e nenhuma célula $\mathbf{F}$ pode ter faces em contato com célula $\mathbf{E}$.

- Células de superfície (S: surface) - possuem fluido em seu interior e têm no mínimo uma face em contato com célula $\mathbf{E}$.

- Células de fronteira (B: boundary) - definem a configuração dos contornos rígidos.

- Células do injetor (I: inflow) - definem a entrada de fluido no domínio.

- Células do ejetor (O: outflow) - definem a saída do fluido no domínio.

A cada ciclo computacional a posição da superfície livre muda, e por isso é necessário reclassificar as células do domínio. Esta atualização é feita de acordo com os seguintes passos descritos em ([OL99], [CF00] e [MF09]): 

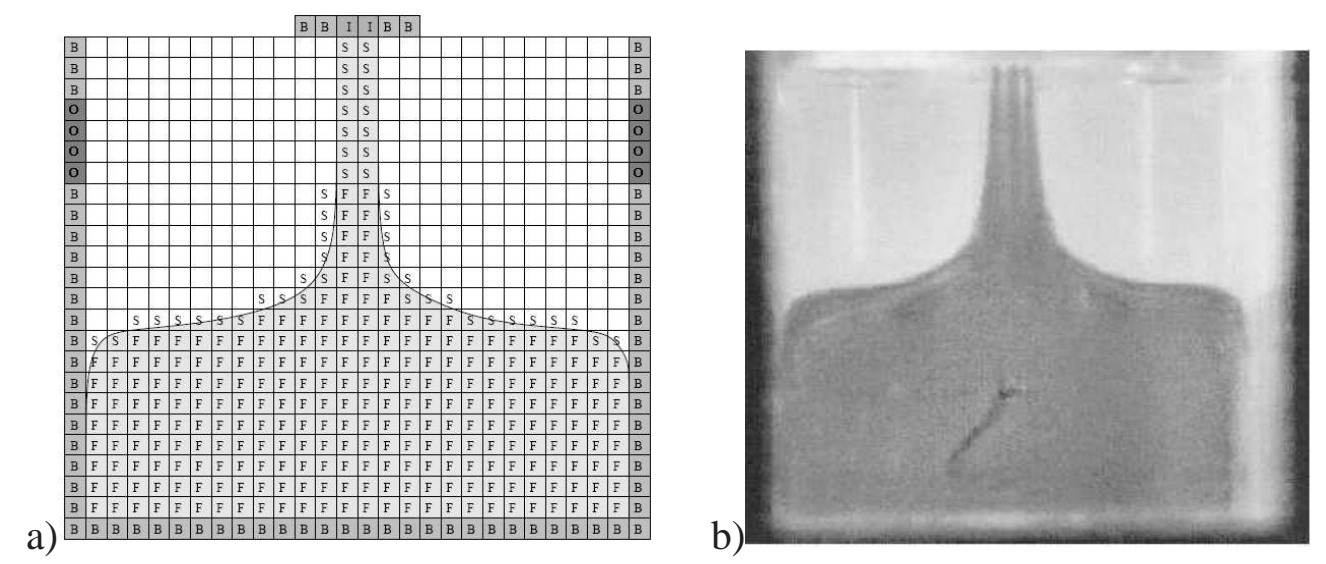

Figura 3.2: Classificação das células do domínio computacional (a) para a simulação do escoamento representado em (b), extraído de [TM99].

- Todas as células $\mathbf{E}$ e $\mathbf{F}$ que abrigam alguma partícula marcadora são alteradas para tipo $\mathbf{S}$.

- Células tipo $\mathbf{S}$ sem interface comum com célula tipo $\mathbf{E}$ se tornam tipo $\mathbf{F}$.

- Células tipo $\mathbf{S}$ sem partícula marcadora se tornam tipo $\mathbf{E}$; todas as grandezas associadas a estas novas células $\mathbf{E}$ passam a ser desconsideradas.

- Células tipo $\mathbf{F}$ com interface comum com célula tipo $\mathbf{E}$ se tornam tipo $\mathbf{S}$.

Um aspecto importante do GENSMAC diz respeito às condições de fronteiras para a superfície livre. Para aplicar as condições dadas pelas equações (2.19) e (2.20), são utilizadas as idéias de [TM93] que exigem um valor para o versor normal $\vec{n}$ de uma célula tipo $\mathbf{S}$.

Para garantir que a superfície livre intercepte cada célula $\mathbf{S}$ uma única vez e em apenas dois lados, admite-se que a malha esteja suficientemente refinada. Desta forma, apenas duas situações são possíveis.

Na primeira delas, assume-se apenas uma aresta comum entre uma célula do tipo $\mathbf{S}$ e uma célula do tipo E. Assim, aproxima-se $\vec{n}$ pela direção paralela a um dos eixos coordenados, como mostrado na Figura 3.3. Logo, o versor normal à superfície livre $\vec{n}$ pode ser definido como:

$$
\vec{n}=\left[\begin{array}{l}
0 \\
1
\end{array}\right], \vec{n}=\left[\begin{array}{l}
1 \\
0
\end{array}\right], \vec{n}=\left[\begin{array}{c}
0 \\
-1
\end{array}\right], \vec{n}=\left[\begin{array}{c}
-1 \\
0
\end{array}\right],
$$

dependendo da posição da célula $\mathbf{E}$ em relação à célula $\mathbf{S}$.

$\mathrm{Na}$ segunda situação, assume-se duas arestas comum entre uma célula do tipo $\mathbf{S}$ e uma célula do tipo E. Assim, aproxima-se $\vec{n}$ por um versor formando ângulo de $45^{\circ} \mathrm{com}$ os eixos coordenados, como mostrado na Figura 3.3. Desta forma, o versor normal pode ser definido como: 


$$
\vec{n}=\left[\begin{array}{c}
\frac{\sqrt{2}}{2} \\
\frac{\sqrt{2}}{2}
\end{array}\right], \vec{n}=\left[\begin{array}{c}
\frac{\sqrt{2}}{2} \\
-\frac{\sqrt{2}}{2}
\end{array}\right], \vec{n}=\left[\begin{array}{c}
-\frac{\sqrt{2}}{2} \\
-\frac{\sqrt{2}}{2}
\end{array}\right], \vec{n}=\left[\begin{array}{c}
-\frac{\sqrt{2}}{2} \\
\frac{\sqrt{2}}{2}
\end{array}\right],
$$

dependendo da posição da célula $\mathbf{E}$ em relação à célula $\mathbf{S}$.

Para os outros tipos de vizinhança entre células do tipo $\mathbf{S}$ e do tipo $\mathbf{E}$, como uma aproximação para $\vec{n}$ não pode ser definida, as equações (2.19) e (2.20) não são aplicadas. Uma possível solução para esse problema é o refinamento da malha.
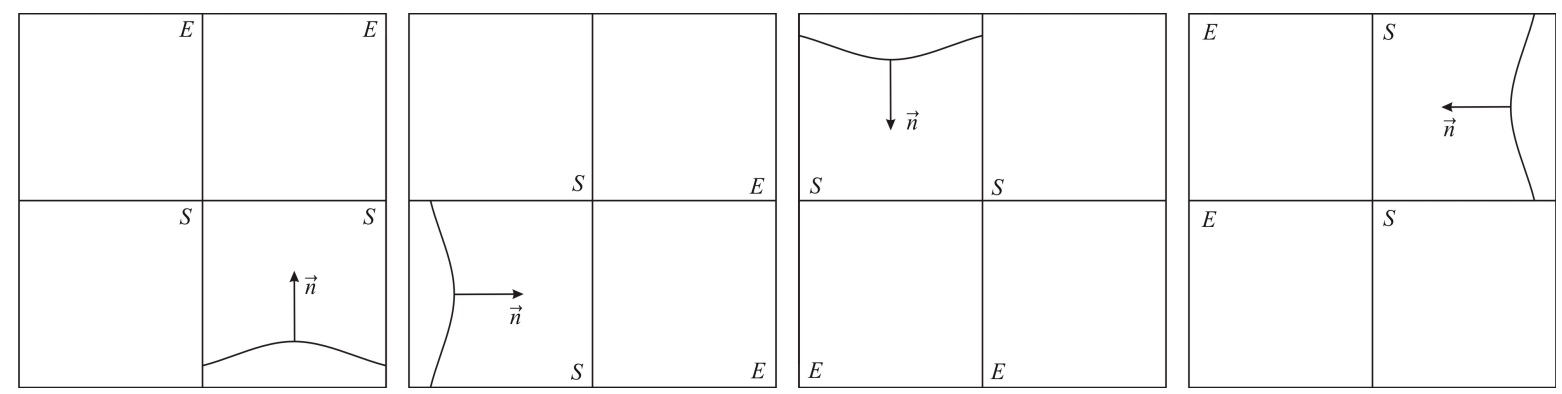

Figura 3.3: Aproximações da superfície livre em célula $\mathbf{S}$ : casos de $90^{\circ}$.
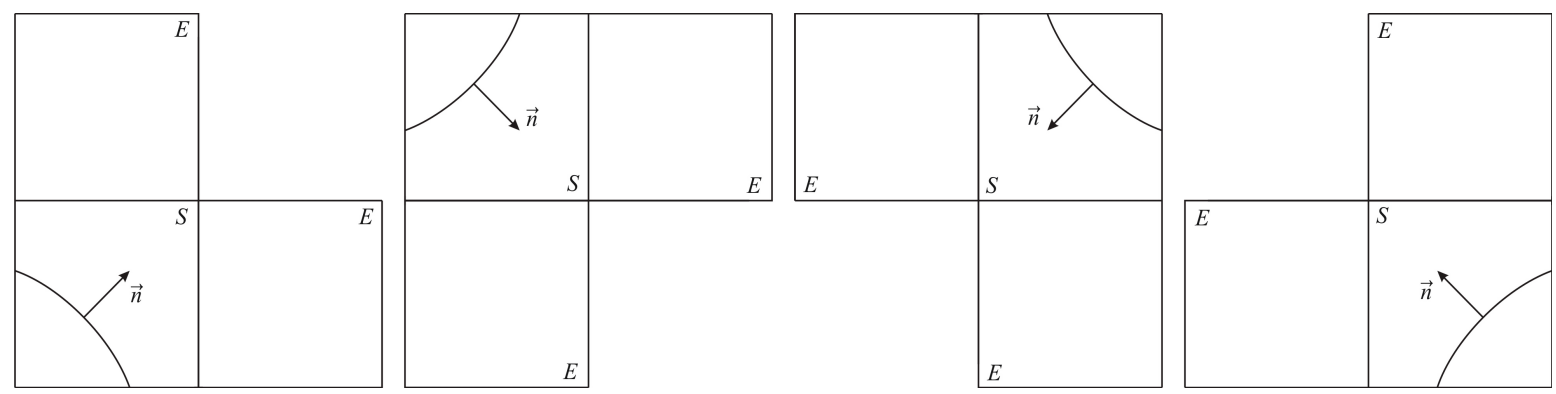

Figura 3.4: Aproximações da superfície livre em célula $\mathbf{S}$ : casos de $45^{\circ}$.

A seguir, apresentamos o GENSMAC como um método de projeção.

\subsection{Método de projeção}

Em razão da complexidade matemática do sistema de EDPs composto pelas equações (2.6) e (2.7), uma grande dificuldade para o tratamento computacional é encontrada. Tal fato ocorre porque a pressão em escoamentos incompressíveis tem como objetivo garantir que a equação da continuidade seja satisfeita em cada passo de tempo. Para facilitar a obtenção de soluções de sistemas deste tipo, vários métodos de aproximações de soluções foram e continuam sendo extensivamente investigados. Estes podem ser classificados, de maneira geral, em métodos segregados e métodos acoplados. 
Os métodos acoplados resolvem as equações (2.6) e (2.7) simultaneamente, calculando $\mathbf{u}$ e $p$ em um mesmo processo. Em termos computacionais, tal fato é bastante incomodo devido à dimensão e às não-linearidades dos sistemas obtidos.

Já em um método segregado, a solução das equações de Navier-Stokes incompressíveis se faz calculando $\mathbf{u}$ e $p$ de forma consecutiva e separada. Assim, esse desacoplamento na solução de $\mathbf{u}$ e $p$ constitui-se num método de projeção ([CH67], [CH68]). A formulação matemática dos métodos de projeção está relacionada com o Teorema de Helmholtz-Hodge (TDHH), cuja demonstração pode ser consultada em [CH00].

Sendo o objetivo deste trabalho o estudo de uma estratégia para o cálculo adaptativo do passo de tempo, uma breve apresentação será feita do método de projeção utilizado no GENSMAC. Mais detalhes podem ser encontrados na sua formulação inicial apresentada em [TM93] e [TM94] que introduziram a Formulação Explícita (FE) e, nos trabalhos recentes [OC08A], [OC08B] e [MF09] que descrevem a Formulação Implícita (FI). Neste trabalho, apresentamos apenas as principais etapas do algoritmo envolvido na FI.

\subsection{Formulação implícita do GENSMAC}

Para a simulação numérica de escoamentos transientes que transcorrem a baixos números de Reynolds as metodologias explícitas requerem restrições rigorosas no passo temporal para estabilidade, acarretando um custo computacional muito alto. Devido à esta limitação, a Formulação Implícita (FI) do GENSMAC foi desenvolvida com o objetivo de eliminar estas restrições nos casos em que $R e \ll 1$.

Modificações recentes na metodologia GENSMAC ([OC04] e [OC06]) resultam num esquema semi-implícito para a discretização da equação da quantidade de movimento. Estes são assim denominados, pois tratam os termos difusivos com esquemas implícitos e os termos convectivos com esquemas explícitos.

Assim, usando o método de Crank-Nicolson $(\mathrm{CN})$ podemos escrever

$$
\begin{aligned}
\frac{\mathbf{u}^{n+1}-\mathbf{u}^{n}}{\Delta t}+\operatorname{conv}(\mathbf{u u})^{n+1 / 2} & =-\nabla p^{n+1}+\frac{1}{R e}\left[\frac{1}{2} \nabla^{2} \mathbf{u}^{n}+\frac{1}{2} \nabla^{2} \mathbf{u}^{n+1}\right]+\frac{1}{F r^{2}} \mathbf{g}^{n+1 / 2}, \\
\nabla \cdot \mathbf{u}^{n+1} & =0,
\end{aligned}
$$

que são aproximações discretas no tempo para (2.6) e (2.7), respectivamente, onde conv $(\mathbf{u u})^{n+1 / 2}$ e $\mathbf{g}^{n+1 / 2}$ são aproximações explícitas para $\nabla \cdot(\mathbf{u u})$ e $\mathbf{g}$ em $t=t_{n+1 / 2}$, respectivamente. Neste trabalho, consideramos o termo convectivo não-linear de (3.5) discretizado no espaço pelo esquema convectivo CUBISTA ([AP03]) e uma aproximação obtida pelo método de Adams-Bashforth ([BU03]) inspirada em [AR97]

$$
\operatorname{conv}(\mathbf{u u})^{n+1 / 2}=\frac{3}{2} \nabla \cdot(\mathbf{u u})^{n}-\frac{1}{2} \nabla \cdot(\mathbf{u u})^{n-1} .
$$


Seja, também,

$$
\frac{\widetilde{\mathbf{u}}-\mathbf{u}^{n}}{\Delta t}+\operatorname{conv}(\mathbf{u u})^{n+1 / 2}=-\nabla \widetilde{p}+\frac{1}{R e}\left[\frac{1}{2} \nabla^{2} \mathbf{u}^{n}+\frac{1}{2} \nabla^{2} \widetilde{\mathbf{u}}\right]+\frac{1}{F r^{2}} \mathbf{g}^{n+1 / 2},
$$

uma aproximação discreta no tempo para o cálculo do campo de velocidade intermediária $\widetilde{\mathbf{u}}$, análoga à equação (3.5), e $\widetilde{p}$ uma aproximação para $p^{n+1}$ que, no GENSMAC, é escolhida como $\widetilde{p}=p^{n}$.

Aplicando o TDHH, sabemos que $\mathbf{u}^{n+1}$ pode ser escrita na forma:

$$
\mathbf{u}^{n+1}=\widetilde{\mathbf{u}}-\nabla \psi^{n+1}
$$

que, juntamente com (3.6), resulta em

$$
\nabla^{2} \psi^{n+1}=\nabla \cdot \widetilde{\mathbf{u}}
$$

Resolvendo (3.8) e (3.10) calculamos respectivamente, $\widetilde{\mathbf{u}}$ e $\psi^{n+1}$, e em seguida calculamos $\mathbf{u}^{n+1}$ por (3.9). Para o cálculo de $p^{n+1}$, podemos substituir (3.9) em (3.8) ([BR01]) e comparando a expressão resultante com (3.5), obtemos,

$$
p^{n+1}=\widetilde{p}+\frac{\psi^{n+1}}{\Delta t}-\frac{1}{2 R e} \nabla^{2} \psi^{n+1}
$$

Assim, encerra-se uma ciclo computacional, movendo-se as partículas marcadoras de acordo com (3.2).

Note que, para determinar $\widetilde{\mathbf{u}}$ e $\psi^{n+1}$ dois sistemas lineares devem ser resolvidos a cada ciclo computacional. Quando (3.8) é discretizada semi-implicitamente, o sistema linear resultante é simétrico, esparso e de grande porte, enquanto que, o sistema resultante de (3.10) é não-simétrico, esparso e de grande porte. No FREEFLOW vários métodos estão implementados para resolver tais sistemas, dentre eles (utilizado desde [OC04]), o método dos Gradientes Conjugados (CG) e o método dos Gradientes Bi-Conjugados com o pré-condicionador de Jacobi (BiCG-Jacobi) para o cálculo de $\widetilde{\mathbf{u}}$ e $\psi^{n+1}$, respectivamente. [MF09] fez um estudo sobre qual método iterativo poderia ser utilizado em substituição ao CG, dentre os mais citados na literatura, BiCG (BiConjugate Gradient), QMR (Quasi-Minimal Residual), TFQMR (Transpose-Free Quasi-Minimal Residual), CGS (Conjugate Gradient Squared) e BiCGstab (BiConjugate Gradient stabilized), o método BiCGstab com pré-condicionador SOR foi considerado a melhor alternativa. Assim, neste trabalho, utilizou-se o método BiCGstab com pré-condicionador SOR com tolerância $\epsilon=1.0 \times 10^{-12}$.

\subsection{Algoritmo Computacional}

$\mathrm{Na}$ seção anterior foram descritas as principais idéias que compõem a estratégia de solução do GENSMAC para simular problemas em duas dimensões. Assim, supondo que a velocidade $\mathbf{u}^{n}$ e a pressão $p^{n}$ são conhecidos em $t=t_{n}$, apresentamos os passos que formam um ciclo computacional, 
o qual permite o cálculo de $\mathbf{u}^{n+1}$ e $p^{n+1}$ em $t_{n+1}=t_{n}+\Delta t$. O algoritmo computacional da FI do GENSMAC ([MF09]) é resumido nos seguintes passos:

Passo 1-FI: cálculo de $\widetilde{u}$ de forma semi-implícita por (3.8).

Passo 2-FI: solução da equação de Poisson (3.10) com a condição de contorno para $\psi^{n+1}$ ao longo da superfície livre dada por (3.9), (2.19) e (3.11), isto é,

$$
\left\{\begin{array}{c}
\mathbf{u}^{n+1}=\widetilde{\mathbf{u}}-\nabla \psi^{n+1} \\
p^{n+1}=\frac{2}{R e}\left[n_{x}^{2} \frac{\partial u^{n+1}}{\partial x}+n_{x} n_{y}\left(\frac{\partial u^{n+1}}{\partial y}+\frac{\partial v^{n+1}}{\partial x}\right)+n_{y}^{2} \frac{\partial v^{n+1}}{\partial y}\right] \\
p^{n+1}=\widetilde{p}+\frac{\psi^{n+1}}{\Delta t}-\frac{1}{2 R e} \nabla^{2} \psi^{n+1}
\end{array}\right.
$$

ou melhor,

$$
\begin{aligned}
\widetilde{p}+\frac{\psi^{n+1}}{\Delta t}-\frac{1}{2 R e} \nabla^{2} \psi^{n+1}= & \frac{2}{R e}\left\{\frac{\partial}{\partial x}\left(\widetilde{u}-\frac{\partial \psi^{n+1}}{\partial x}\right) n_{x}^{2}+\frac{\partial}{\partial y}\left(\widetilde{v}-\frac{\partial \psi^{n+1}}{\partial y}\right) n_{y}^{2}\right. \\
+ & {\left.\left[\frac{\partial}{\partial y}\left(\widetilde{u}-\frac{\partial \psi^{n+1}}{\partial x}\right)+\frac{\partial}{\partial x}\left(\widetilde{v}-\frac{\partial \psi^{n+1}}{\partial y}\right)\right] n_{x} n_{y}\right\} . }
\end{aligned}
$$

Passo 3-FI: cálculo da velocidade $\mathbf{u}^{n+1}$ usando (3.9) no interior do domínio e as equações (2.20) e (3.6) na superfície livre, isto é,

$$
\begin{aligned}
2 n_{x} n_{y}\left(\frac{\partial v^{n+1}}{\partial y}-\frac{\partial u^{n+1}}{\partial x}\right)+\left(n_{x}^{2}-n_{y}^{2}\right)\left(\frac{\partial u^{n+1}}{\partial y}+\frac{\partial v^{n+1}}{\partial x}\right) & =0 \\
\frac{\partial u^{n+1}}{\partial x}+\frac{\partial v^{n+1}}{\partial y} & =0
\end{aligned}
$$

Passo 4-FI: cálculo da pressão $p^{n+1}$ por (3.11) tanto no interior do domínio quanto na superfície livre, isto é, em células $\mathbf{F}$ e $\mathbf{S}$; em células $\mathbf{E}$ adotamos, como condição de contorno,

$$
\psi^{n+1}=0 .
$$

Passo 5-FI: cálculo da nova posição $\mathrm{x}^{n+1}$ das partículas que definem a superfície livre, resolvendo (3.2) por Euler Explícito, isto é,

$$
\frac{\mathbf{x}^{n+1}-\mathbf{x}^{n}}{\Delta t}=\mathbf{u}\left(\mathbf{x}^{n}, t_{n+1}\right) .
$$




\subsection{Cálculo do passo de tempo}

O GENSMAC utiliza um passo temporal variável, sendo este calculado a cada ciclo computacional, de acordo com a restrição de estabilidade da FE, gerando duas limitações para $\Delta t$.

A primeira limitação, imposta pelo tratamento dado ao termo não-linear da equação de conservação do momento, resulta no chamado $\Delta t_{C F L}$, dado por

$$
\Delta t_{C F L}=\min \left\{\Delta t_{C F L x}, \Delta t_{C F L y}\right\}
$$

onde

$$
\begin{aligned}
& \frac{\Delta t_{C F L x} \max \left\{\left|u^{n}\right|\right\}}{\Delta x} \leqslant \frac{1}{2}, \\
& \frac{\Delta t_{C F L y} \max \left\{\left|v^{n}\right|\right\}}{\Delta y} \leqslant \frac{1}{2},
\end{aligned}
$$

expressam a condição "Courant-Friedrichs-Lewy - CFL " ([FL91]) ao longo das direções $x$ e $y$, respectivamente.

A segunda limitação é a restrição de estabilidade parabólica, sendo $\Delta t_{v i s c}$, o passo temporal adimensional resultante da condição de estabilidade nos termos viscosos, dado por

$$
\Delta t_{v i s c}=\frac{R e}{2}\left[\frac{1}{(\Delta x)^{2}}+\frac{1}{(\Delta y)^{2}}\right]^{-1}=\frac{R e}{4}(\Delta m)^{2} .
$$

Dessa forma, o passo temporal da FE é definido como

$$
\Delta t=F_{o} \min \left\{F_{v i s c} \Delta t_{v i s c}, F_{C F L} \Delta t_{C F L}\right\}
$$

onde $F_{o}, F_{v i s c}, F_{C F L}$ são fatores empíricos de controle do passo no tempo, tomados no intervalo ]0, 1] para garantir estabilidade e precisão dos resultados.

Pelas equações (3.17) e (3.20), para $R e \ll 1$ ou para uma malha muito refinada,

$$
\Delta t_{v i s c}=O\left[R e(\Delta m)^{2}\right] \ll \Delta t_{C F L}=O(\Delta m) \text {, }
$$

fazendo com que a FE exija um passo temporal muito pequeno, escolhido por imposição da estabilidade e não da precisão. Desta forma, a FE apresenta um elevado número de ciclos computacionais, o que implica em elevado tempo de processamento.

A FI do GENSMAC ([OC04], [OC06], [OC08B]) descrita na seção 3.4, melhora a restrição de estabilidade parabólica em escoamentos com superfícies livres, aumentando o passo temporal e, consequentemente, reduzindo o custo computacional. O Passo 1-FI elimina a restrição parabólica em escoamentos confinados e, os Passo 2-FI e 4-FI calculam a pressão ao longo da superfície livre de forma implícita o que proporciona um ganho de estabilidade semelhante ao dos casos confinados 
([MF09]).

Assim, torna-se teoricamente possível eliminar a segunda limitação ao $\Delta t$ descrita em (3.20). No entanto, a condição $C F L$ em (3.18) e (3.19) permanece para a FI. Como $\Delta t_{C F L}$ pode, em geral, tomar valores grandes, torna-se necessário introduzir critérios que garantam também a precisão do método. 
CAPÍTULO 4

\section{GENSMAC com Passo Temporal Adaptativo}

\subsection{Introdução}

Como já observado, a restrição no passo temporal imposta pela fórmula (3.21) para o método explícito representa uma grande inconveniência na aplicação desse método para algumas classes de problemas. Comentamos no capítulo anterior também que uma tentativa bem sucedida de contornar esse problema, pelo menos do ponto de vista teórico, foi obtida nos trabalhos [OC06], [OC08A] e [OC08B]. Mas, na prática, mesmo no caso dos métodos semi-implícitos, o passo temporal não pode aumentar além de certos limites, bem aquém daquele da condição $C F L$, sem provocar sérios problemas de precisão nos resultados numéricos e consequente aparecimento de resultados não físicos. Portanto, mesmo na formulação semi-implícita uma restrição no passo temporal da forma (3.21) é aplicada, e dai surge a necessidade de providenciar valores para o fator $F_{v i s c}$.

Em [MF09] foi mostrado que para problemas com $R e \ll 1$, a solução numérica utilizando $F_{\text {visc }}>$ 1 concorda com a solução numérica da formulação explícita utilizando $F_{\text {visc }}<1$. Embora esses resultados sejam adequados, a presença da fórmula (3.21) é bastante inconveniente do ponto de vista prático uma vez que contém fatores de escala $F_{0}, F_{v i s c}$ e $F_{C F L}$ que são fatores empíricos e escolhidos sem um critério teórico e mantidos fixos ao longo de toda a simulação.

Uma maneira de contornar esse problema, é utilizar uma estratégia de cálculo de passo temporal adaptativo, que leve em consideração informações do próprio escoamento, como descrito em [GP08] e [KD10]. Esses autores descrevem técnicas numéricas bem fundamentadas na análise matemática para a escolha do passo temporal, considerando escoamentos confinados.

Neste capítulo vamos descrever a adaptação dessa técnica para o caso de escoamentos com super- 
fícies livres.

\subsection{Método com Passo Temporal Adaptativo}

Técnicas adaptativas para seleção de passo de tempo são geralmente baseadas em medidas do Erro de Truncamento Local (ETL), que após algumas manipulações, pode ser expresso pela diferença entre as soluções de dois métodos numéricos. Neste trabalho, utiliza-se dois métodos da família Adams, o método implícito de Crank-Nicolson $(\mathrm{CN})$ e o método explícito de Adams-Bashforth de segunda ordem com passo de tempo variável (AB2).

A equação de interesse é dada por (2.6), reescrita aqui,

$$
\frac{\partial \mathbf{u}}{\partial t}+\nabla \cdot(\mathbf{u u})=-\nabla p+\frac{1}{R e} \nabla^{2} \mathbf{u}+\frac{1}{F r^{2}} \mathbf{g}
$$

que sem perda de generalidade depois da discretização nas variáveis espaciais, podemos considerá-la como uma EDO da forma

$$
\frac{\partial \mathbf{u}}{\partial t}=\mathbf{f}(t, \mathbf{u}(t))
$$

com condição inicial

$$
\mathbf{u}(0)=\mathbf{u}^{0}
$$

O algoritmo de passo temporal adaptativo que é aplicado à EDO (4.1) é uma versão adaptada do integrador inteligente de [GS00B] e é composta de duas etapas: integração no tempo e método de seleção do passo de tempo.

Nas próximas subseções uma discussão sobre cada uma dessas etapas será apresentada.

\subsubsection{Integração no tempo}

Nesta subseção serão deduzidos os métodos $\mathrm{CN}$ e $\mathrm{AB} 2$ e a fórmula para os erros de truncamento local.

Os métodos de Adams são obtidos por interpolação polinomial, sobre um conjunto de pontos não necessariamente igualmente espaçados. Os métodos implícitos são chamados métodos de Adams-Moulton, e neste trabalho, utiliza-se o método de CN. Logo, a expressão para CN é obtida integrando (4.1) de $t_{n}$ a $t_{n+1}$,

$$
\begin{aligned}
\int_{t_{n}}^{t_{n+1}} \frac{\partial \mathbf{u}}{\partial t} d s & =\int_{t_{n}}^{t_{n+1}} f(s, \mathbf{u}(s)) d s \\
\mathbf{u}\left(t_{n+1}\right)-\mathbf{u}\left(t_{n}\right) & =\int_{t_{n}}^{t_{n+1}} f(s, \mathbf{u}(s)) d s .
\end{aligned}
$$


Um método de Adams consiste em aproximar a função $f(s, \mathbf{u}(s))$, pelo seu polinômio interpolador, e então integrar tal polinômio obtendo assim uma aproximação para $\mathbf{u}\left(t_{n+1}\right)$. Usando um polinômio de grau 1 para interpolar $f(s, \mathbf{u}(s))$, segue

$$
\mathbf{u}\left(t_{n+1}\right)-\mathbf{u}\left(t_{n}\right)=\int_{t_{n}}^{t_{n+1}} P_{1}(s, \mathbf{u}(s)) d s+E T L .
$$

Como, $\frac{\partial \mathbf{u}}{\partial t}=f(s, \mathbf{u}(s))$ e o polinômio interpolador é a reta que passa por $\left(t_{n}, \frac{\partial \mathbf{u}\left(t_{n}\right)}{\partial t}\right)$ e $\left(t_{n+1}, \frac{\partial \mathbf{u}\left(t_{n+1}\right)}{\partial t}\right)$, temos:

$$
\begin{aligned}
\mathbf{u}\left(t_{n+1}\right)-\mathbf{u}\left(t_{n}\right)= & \int_{t_{n}}^{t_{n+1}}\left[-\frac{\left(s-t_{n+1}\right)}{\Delta t_{n}} \frac{\partial \mathbf{u}\left(t_{n+1}\right)}{\partial t}+\frac{\left(s-t_{n}\right)}{\Delta t_{n}} \frac{\partial \mathbf{u}\left(t_{n}\right)}{\partial t}\right] d s+E T L \\
= & -\left.\frac{1}{\Delta t_{n}}\left(\frac{s^{2}}{2}-s t_{n+1}\right)\right|_{t_{n}} ^{t_{n+1}} \frac{\partial \mathbf{u}\left(t_{n+1}\right)}{\partial t}+\left.\frac{1}{\Delta t_{n}}\left(\frac{s^{2}}{2}-s t_{n}\right)\right|_{t_{n}} ^{t_{n+1}} \frac{\partial \mathbf{u}\left(t_{n}\right)}{\partial t} \\
& +E T L \\
= & -\frac{1}{\Delta t_{n}}\left[\frac{\left(t_{n+1}\right)^{2}-t_{n}^{2}}{2}-t_{n+1}^{2}+t_{n} t_{n+1}\right] \frac{\partial \mathbf{u}\left(t_{n+1}\right)}{\partial t} \\
& +\frac{1}{\Delta t_{n}}\left[\frac{\left(t_{n+1}\right)^{2}-t_{n}^{2}}{2}-t_{n+1} t_{n}+t_{n}^{2}\right] \frac{\partial \mathbf{u}\left(t_{n}\right)}{\partial t}+E T L .
\end{aligned}
$$

Definindo $t_{n+1}=t_{n}+\Delta t_{n}$, e substituindo em (4.6), segue

$$
\begin{aligned}
\mathbf{u}\left(t_{n+1}\right)-\mathbf{u}\left(t_{n}\right)= & -\frac{1}{\Delta t_{n}}\left[\frac{\left(t_{n}+\Delta t_{n}\right)^{2}-t_{n}^{2}}{2}-\left(t_{n}+\Delta t_{n}\right)^{2}+t_{n}\left(t_{n}+\Delta t_{n}\right)\right] \frac{\partial \mathbf{u}\left(t_{n+1}\right)}{\partial t} \\
& +\frac{1}{\Delta t_{n}}\left[\frac{\left(t_{n}+\Delta t_{n}\right)^{2}-t_{n}^{2}}{2}-\left(t_{n}+\Delta t_{n}\right) t_{n}+t_{n}^{2}\right] \frac{\partial \mathbf{u}\left(t_{n}\right)}{\partial t}+\text { ETL. }
\end{aligned}
$$

Desta forma, dado um vetor $\mathbf{u}^{n}$ que aproxima a solução exata $\mathbf{u}\left(t_{n}\right)$ no tempo $t_{n}$, isto é, $\mathbf{u}^{n} \approx \mathbf{u}\left(t_{n}\right)$ e um passo de tempo $\Delta t_{n}$, o vetor $\mathbf{u}^{n+1} \approx \mathbf{u}\left(t_{n}+\Delta t_{n}\right)$ é calculado resolvendo-se o sistema implícito

$$
\mathbf{u}^{n+1}=\mathbf{u}^{n}+\frac{\Delta t_{n}}{2}\left({\frac{\partial \mathbf{u}^{n+1}}{\partial t}}^{n}+\frac{\partial \mathbf{u}^{n}}{\partial t}\right)
$$

O ETL é dado por 


$$
\begin{aligned}
& \mathbf{u}^{n+1}-\mathbf{u}\left(t_{n+1}\right)=\mathbf{u}^{n}+\frac{\Delta t_{n}}{2}\left({\frac{\partial \mathbf{u}^{n+1}}{\partial t}}^{n}+\frac{\partial \mathbf{u}^{n}}{\partial t}\right)-\mathbf{u}\left(t_{n+1}\right)
\end{aligned}
$$

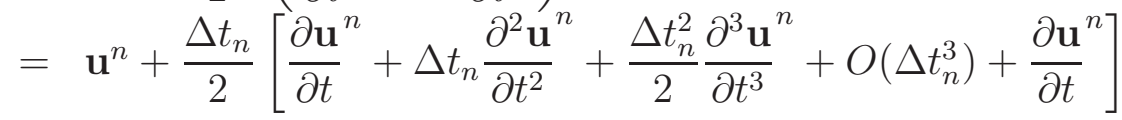

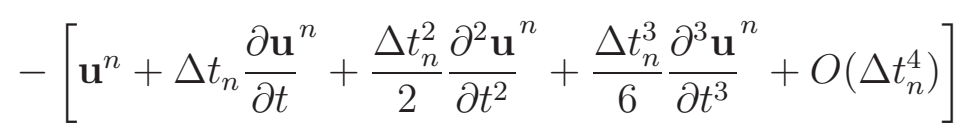

$$
\begin{aligned}
& =\frac{\Delta t_{n}^{3}}{12} \frac{\partial^{3} \mathbf{u}^{n}}{\partial t^{3}}+O\left(\Delta t_{n}^{4}\right)
\end{aligned}
$$

Assim, uma estimativa para o ETL para o método de CN no instante de tempo $t_{n}$ é dada por

$$
\mathbf{e}^{n} \simeq \frac{\Delta t_{n}^{3}}{12} \frac{\partial^{3} \mathbf{u}^{n}}{\partial t^{3}}
$$

O método de $\mathrm{CN}$ é usado pelo fato de ser condicionalmente estável de precisão condizente com a discretização espacial de segunda ordem. Outros métodos, como Euler Implícito, são exemplificados em [GS00A].

Analogamente, para formular a expressão para AB2, novamente integra-se (4.1) de $t_{n}$ a $t_{n+1}$ e neste caso, o polinômio interpolador é a reta que passa por $\left(t_{n}, \frac{\partial \mathbf{u}\left(t_{n}\right)}{\partial t}\right)$ e $\left(t_{n-1}, \frac{\partial \mathbf{u}\left(t_{n-1}\right)}{\partial t}\right)$. Logo:

$$
\begin{aligned}
\mathbf{u}\left(t_{n+1}\right)-\mathbf{u}\left(t_{n}\right)= & \int_{t_{n}}^{t_{n+1}}\left[-\frac{\left(s-t_{n}\right)}{\Delta t_{n-1}} \frac{\partial \mathbf{u}\left(t_{n-1}\right)}{\partial t}+\frac{s-t_{n-1}}{\Delta t_{n-1}} \frac{\partial \mathbf{u}\left(t_{n}\right)}{\partial t}\right] d s+E T L \\
= & -\left.\frac{1}{\Delta t_{n-1}}\left(\frac{s^{2}}{2}-s t_{n}\right)\right|_{t_{n}} ^{t_{n+1}} \frac{\partial \mathbf{u}\left(t_{n-1}\right)}{\partial t}+\left.\frac{1}{\Delta t_{n-1}}\left(\frac{s^{2}}{2}-s t_{n-1}\right)\right|_{t_{n}} ^{t_{n+1}} \frac{\partial \mathbf{u}\left(t_{n}\right)}{\partial t} \\
& +E T L \\
= & -\frac{1}{\Delta t_{n-1}}\left[\frac{\left(t_{n+1}\right)^{2}-t_{n}^{2}}{2}-t_{n+1} t_{n}+t_{n}^{2}\right] \frac{\partial \mathbf{u}\left(t_{n-1}\right)}{\partial t} \\
& +\frac{1}{\Delta t_{n-1}}\left[\frac{\left(t_{n+1}\right)^{2}-t_{n}^{2}}{2}-t_{n+1} t_{n-1}+t_{n} t_{n-1}\right] \frac{\partial \mathbf{u}\left(t_{n}\right)}{\partial t}+E T L .
\end{aligned}
$$

Lembrando que $t_{n+1}=t_{n}+\Delta t_{n}$ e $t_{n-1}=t_{n}-\Delta t_{n-1}$, substituindo em (4.11), segue 


$$
\begin{aligned}
\mathbf{u}\left(t_{n+1}\right)- & \mathbf{u}\left(t_{n}\right)=-\frac{1}{\Delta t_{n-1}}\left[\frac{\left(t_{n}+\Delta t_{n}\right)^{2}-t_{n}^{2}}{2}-\left(t_{n}+\Delta t_{n}\right) t_{n}+t_{n}^{2}\right] \frac{\partial \mathbf{u}\left(t_{n-1}\right)}{\partial t} \\
& +\frac{1}{\Delta t_{n-1}}\left[\frac{\left(t_{n}+\Delta t_{n}\right)^{2}-t_{n}^{2}}{2}-\left(t_{n}+\Delta t_{n}\right)\left(t_{n}-\Delta t_{n-1}\right)-t_{n}\left(t_{n}-\Delta t_{n-1}\right)\right] \frac{\partial \mathbf{u}\left(t_{n}\right)}{\partial t} \\
& +E T L .
\end{aligned}
$$

Rearranjando os termos, temos uma expressão para o método explícito de Adams-Bashforth de segunda ordem com passo de tempo variável,

$$
\mathbf{u}_{*}^{n+1}=\mathbf{u}^{n}+\frac{\Delta t_{n}}{2}\left[\left(2+\frac{\Delta t_{n}}{\Delta t_{n-1}}\right) \frac{\partial \mathbf{u}^{n}}{\partial t}-\left(\frac{\Delta t_{n}}{\Delta t_{n-1}}\right) \frac{\partial \mathbf{u}^{n-1}}{\partial t}\right],
$$

com ETL dado por

$$
\begin{aligned}
& \mathbf{u}_{*}^{n+1}-\mathbf{u}\left(t_{n+1}\right)=\mathbf{u}^{n}+\frac{\Delta t_{n}}{2}\left[\left(2+\frac{\Delta t_{n}}{\Delta t_{n-1}}\right) \frac{\partial \mathbf{u}^{n}}{\partial t}-\left(\frac{\Delta t_{n}}{\Delta t_{n-1}}\right) \frac{\partial \mathbf{u}^{n-1}}{\partial t}\right]-\mathbf{u}\left(t_{n+1}\right) \\
& =\mathbf{u}^{n}+\frac{\Delta t_{n}}{2}\left[\left(2+\frac{\Delta t_{n}}{\Delta t_{n-1}}\right) \frac{\partial \mathbf{u}^{n}}{\partial t}\right.
\end{aligned}
$$

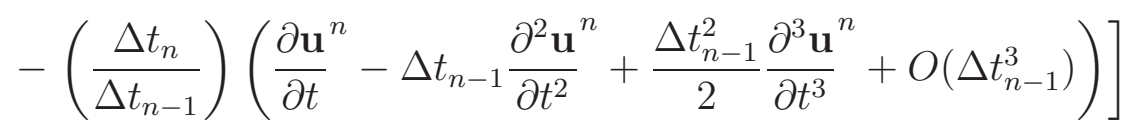

$$
\begin{aligned}
& -\left[\mathbf{u}^{n}+\Delta t_{n} \frac{\partial \mathbf{u}^{n}}{\partial t}+\frac{\Delta t_{n}^{2}}{2} \frac{\partial^{2} \mathbf{u}^{n}}{\partial t^{2}}+\frac{\Delta t_{n}^{3}}{6} \frac{\partial^{3} \mathbf{u}^{n}}{\partial t^{3}}+O\left(\Delta t_{n}^{4}\right)\right] \\
& =-\left(2+3 \frac{\Delta t_{n-1}}{\Delta t_{n}}\right) \frac{\Delta t_{n}^{3}}{12} \frac{\partial^{3} \mathbf{u}^{n}}{\partial t^{3}}+O\left(\Delta t_{n}^{4}\right)
\end{aligned}
$$

onde o índice $\left(_{*}\right)$ foi acrescido ao vetor $\mathbf{u}$ para diferenciar do vetor utilizado no CN. O ETL de AB2 será utilizado para estimar o ETL de CN. Logo, comparando (4.14) e (4.9), segue

$$
\mathbf{u}^{n+1}-\mathbf{u}_{*}^{n+1}=\frac{\Delta t_{n}^{3}}{12} \frac{\partial^{3} \mathbf{u}^{n}}{\partial t^{3}} 3\left(1+\frac{\Delta t_{n-1}}{\Delta t_{n}}\right) .
$$

Em (4.15) usando (4.10), o ETL de CN é reescrito como

$$
\mathbf{e}^{n}=\frac{\mathbf{u}^{n+1}-\mathbf{u}_{*}^{n+1}}{3\left(1+\frac{\Delta t_{n-1}}{\Delta t_{n}}\right)}
$$


ou seja, o ETL de $\mathrm{CN}$ é proporcional à diferença entre as soluções de $\mathrm{CN}$ e $\mathrm{AB} 2$, com uma constante de proporcionalidade conhecida.

A próxima etapa, Seleção do passo de tempo, irá mostrar como mensurar o erro, e com isso, formular uma expressão para o cálculo do passo de tempo.

\subsubsection{Método de seleção do passo de tempo}

Para controlar a integração no tempo é usual colocar uma tolerância $\varepsilon$, sobre a norma de $\mathbf{e}^{n}$, isto é, pedir que:

$$
\left\|\mathbf{e}^{n+1}\right\| \leq \varepsilon
$$

Para o problema (4.1), segundo [GS00B], uma melhor escolha para o cálculo da norma $\left\|\mathbf{e}^{n+1}\right\|$ é a norma euclidiana ponderada (RMS):

$$
\left\|\mathbf{e}^{n}\right\|^{2}=\frac{1}{N_{u}+N_{v}}\left[\sum^{N u}\left(\frac{e_{u}^{n+1}}{\left|u^{n+1}\right|+U_{0}}\right)^{2}+\sum^{N v}\left(\frac{e_{v}^{n+1}}{\left|v^{n+1}\right|+U_{0}}\right)^{2}\right],
$$

onde $U_{0}$ é uma velocidade característica, $|\cdot|$ o máximo da velocidade em cada ciclo e $N_{u}+N_{v}=N_{T}$ o total de células onde se calcula a velocidade.

O próximo passo, é calcular o passo de tempo $\Delta t_{n+1}$ e isso será feito usando o ETL dado por (4.16). Logo, se calcularmos a razão de sucessivos erros de truncamento, teremos

$$
\frac{\left\|\mathbf{e}^{n+1}\right\|}{\left\|\mathbf{e}^{n}\right\|} \approx \frac{\frac{\Delta t_{n+1}^{3}}{12} \frac{\partial^{3} \mathbf{u}^{n+1}}{\partial t^{3}}}{\frac{\Delta t_{n}^{3}}{12} \frac{\partial^{3} \mathbf{u}^{n}}{\partial t^{3}}}
$$

e assumindo que a solução do sistema de EDO tem derivadas de terceira ordem suave no tempo, isto é, a integração temporal usando CN é na verdade de segunda ordem, segue que

$$
\left\|\mathbf{e}^{n}\right\| \approx\left\|\mathbf{e}^{n+1}\right\|\left(\frac{\Delta t_{n}}{\Delta t_{n+1}}\right)^{3}
$$

Usando (4.17), temos que a razão de sucessivos erros de truncamento é proporcional ao cubo da razão de sucessivos passos de tempo, ou seja,

$$
\left\|\mathbf{e}^{n}\right\|\left(\frac{\Delta t_{n+1}}{\Delta t_{n}}\right)^{3} \lesssim \varepsilon .
$$

Assim, considerando o passo de tempo adaptativo $\Delta t_{A D A P}$ como sendo $\Delta t_{n+1}$ e invocando a igualdade, formulamos a seguinte heurística para seleção do passo de tempo

$$
\Delta t_{A D A P}=\Delta t_{n}\left(\frac{\varepsilon}{\left\|\mathbf{e}^{n}\right\|}\right)^{1 / 3}
$$


Desta forma, o passo de tempo para o próximo ciclo é dado por

$$
\Delta t_{n+1}=\min \left\{\Delta t_{A D A P}, \Delta t_{C F L}\right\}
$$

A condição $C F L$ ainda continuará presente, pois ela é consequência do tratamento dado aos termos não-lineares da equação de conservação de momento.

Para implementar esta metodologia na prática, duas questões devem ser consideradas.

- O método AB2 não é auto-inicializante. Assim, na primeira iteração, $n=0$, ao resolver o sistema implícito (4.8), usando (2.6), calcula-se

$$
\frac{\partial \mathbf{u}^{0}}{\partial t}=-\nabla \cdot(\mathbf{u u})^{0}-\nabla p^{0}+\frac{1}{R e} \nabla^{2} \mathbf{u}^{0}+\frac{1}{F r^{2}} \mathbf{g}^{0}
$$

para inicializar AB2 na segunda iteração.

- A escolha do passo de tempo inicial $\Delta t_{0}$. Várias estratégias estão disponíveis para iniciar CN ([GP08]). Aqui escolhemos um valor pequeno, como $\Delta t_{0}=1.0 \times 10^{-6}$, e espera-se que o algoritmo aumente $\Delta t$ rapidamente.

O algoritmo admitindo-se $\Delta t_{1}=\Delta t_{0}$ fica então:

Passo 1-ADAP: Usando CN, resolve-se um sistema linear para determinar $\mathbf{u}^{n+1}$, isto é, determina-se $\widetilde{\mathbf{u}}$ utilizando (3.8), reescrita aqui

$$
\frac{\widetilde{\mathbf{u}}-\mathbf{u}^{n}}{\Delta t}+\operatorname{conv}(\mathbf{u u})^{n+1 / 2}=-\nabla \widetilde{p}+\frac{1}{R e}\left[\frac{1}{2} \nabla^{2} \mathbf{u}^{n}+\frac{1}{2} \nabla^{2} \widetilde{\mathbf{u}}\right]+\frac{1}{F r^{2}} \mathbf{g}^{n+1 / 2}
$$

Passo 2-ADAP: Usando AB2, calcula-se $\mathbf{u}_{*}$ explicitamente por:

$$
\widetilde{\mathbf{u}}_{*}=\mathbf{u}^{n}+\frac{\Delta t_{n}}{2}\left[\left(2+\frac{\Delta t_{n}}{\Delta t_{n-1}}\right) \frac{\partial \mathbf{u}^{n}}{\partial t}-\left(\frac{\Delta t_{n}}{\Delta t_{n-1}}\right) \frac{\partial \mathbf{u}^{n-1}}{\partial t}\right]
$$

Passo 3-ADAP: Calcula-se o ETL de CN usando o ETL de AB2 (4.16),

$$
\mathbf{e}^{n}=\frac{\widetilde{\mathbf{u}}-\widetilde{\mathbf{u}}_{*}}{3\left(1+\frac{\Delta t_{n-1}}{\Delta t_{n}}\right)} .
$$

A seguinte estratégia é aplicada para determinar $\Delta t$ : aumentar $\Delta t$ sempre que possível, diminuir $\Delta t$ somente quando necessário, ou seja, os passos de tempo são selecionados para seguir a física do problema. 
Passo 4-ADAP: Se $\left\|\mathbf{e}^{n}\right\|>\varepsilon\left(\frac{1}{0.7}\right)^{1 / 3}$, reduzimos o passo de tempo

$$
\Delta t_{A D A P}=\Delta t_{n}\left(\frac{\varepsilon}{\left\|\mathbf{e}^{n}\right\|}\right)^{1 / 3},
$$

impondo a condição $C F L$, o passo de tempo para o ciclo atual é dado por

$$
\Delta t_{n+1}=\min \left\{\Delta t_{A D A P}, \Delta t_{C F L}\right\}
$$

e voltamos ao Passo 1-ADAP. Caso contrário, aceitamos a solução calculada pelo Passo 1-ADAP e fazemos $t_{n+1}=t_{n}+\Delta t_{n+1}$.

Obs.: Caso ocorra mais que 10 reduções no mesmo ciclo, uma mensagem de erro é emitida e paramos a simulação para uma análise mais detalhada. A constante 0.7 foi adotada como sugerido em [KD10].

Passo 5-ADAP: Se $\left\|\mathbf{e}^{n}\right\|<\varepsilon$ calculamos o passo de tempo inicial para o próximo ciclo

$$
\Delta t_{A D A P}=\Delta t_{n}\left(\frac{\varepsilon}{\left\|\mathbf{e}^{n}\right\|}\right)^{1 / 3}
$$

impondo a condição $C F L$, segue

$$
\Delta t_{n+1}=\min \left\{\Delta t_{A D A P}, \Delta t_{C F L}\right\}
$$

Caso contrário, temos

$$
\varepsilon<\left\|\mathbf{e}^{n}\right\|<\varepsilon\left(\frac{1}{0.7}\right)^{1 / 3},
$$

e não alteramos o passo de tempo, ou seja, $\Delta t_{n+1}=\Delta t_{n}$.

A técnica descrita foi aplicada à equação (3.8) uma vez que aplicá-la à equação (3.9) exigiria resolver a equação de Poisson (3.10) a cada vez que o passo de tempo fosse rejeitado levando a um aumento no custo computacional. Além do mais o interesse é na discretização temporal das equações de momento o que não envolve a equação de Poisson.

Um algoritmo alternativo, equivalente na teoria, mas mais preciso em face ao erro de arredondamento, é resolver o sistema (4.24) na variável $\widetilde{\mathbf{d}}^{n}$, admitindo:

$$
\widetilde{\mathbf{d}}^{n}=\frac{\widetilde{\mathbf{u}}-\mathbf{u}^{n}}{\Delta t_{n}},
$$

Desta forma, no Passo 1-ADAP, resolvemos o sistema 


$$
\widetilde{\mathbf{d}}^{n}-\frac{\Delta t}{2 R e} \nabla^{2} \widetilde{\mathbf{d}}=\frac{\partial \mathbf{u}^{n}}{\partial t}
$$

sendo

$$
\frac{\partial \mathbf{u}^{n}}{\partial t}=-\operatorname{conv}(\mathbf{u u})^{n+1 / 2}-\nabla \widetilde{p}+\frac{1}{R e} \nabla^{2} \mathbf{u}^{n}+\frac{1}{F r^{2}} \mathbf{g}^{n+1 / 2},
$$

a atualização para a derivada utilizada em AB2. Com esta mudança de variável, o custo computacional para AB2 torna-se insignificante. Por fim, atualiza-se a solução, calculando

$$
\widetilde{\mathbf{u}}=\mathbf{u}^{n}+\Delta t_{n} \widetilde{\mathbf{d}}^{n}
$$

Ainda em [KD10], uma terceira etapa é apresentada, a chamada estabilização do integrador. Esta se faz necessária, pois o método de CN é propenso a oscilações ao resolver problemas stiff com tolerâncias grandes no passo de tempo ou no fim de uma simulação, quando perto do estado estacionário. Com isso, o passo de tempo cresce assintoticamente e não como deveria, isto é, o passo de tempo deveria aumentar com o tempo. A estratégia para contornar esse problema é denominada média no passo de tempo. A média é invocada periodicamente a cada $n_{*}$ passos. Para tal passo, depois de calculada a solução $\mathbf{d}^{n}$, definimos uma nova solução deslocada tal que

$$
\begin{aligned}
\mathbf{u}^{n} & =\frac{1}{2}\left(\mathbf{u}^{n}+\mathbf{u}^{n-1}\right), & \frac{\partial \mathbf{u}^{n}}{\partial t} & =\frac{1}{2}\left(\frac{\partial \mathbf{u}^{n}}{\partial t}+\frac{\partial \mathbf{u}^{n-1}}{\partial t}\right) \\
\mathbf{u}^{n+1} & =\mathbf{u}^{n}+\frac{1}{2} \Delta t_{n} \mathbf{d}^{n}, & \frac{\partial \mathbf{u}^{n+1}}{\partial t} & =\mathbf{d}^{n} .
\end{aligned}
$$

sendo

$$
\mathbf{d}^{n}=\frac{\mathbf{u}^{n+1}-\mathbf{u}^{n}}{\Delta t_{n}}
$$

Assim, calcula-se o próximo passo de tempo usando (4.22) e a integração é continuada. O processo de média extingue qualquer contribuição da forma $(-1)^{n}$ presente na solução e em sua derivada temporal, reduzindo assim as oscilações mantendo segunda ordem de precisão.

No GENSMAC tal etapa se faz desnecessária uma vez que a condição $C F L$ imposta no cálculo do passo de tempo ainda continuará a existir, pois ela garante que uma partícula de fluido não percorrerá, em cada passo de tempo, uma distância maior que o tamanho de uma célula. Desta forma, $\Delta t_{C F L}$ servirá como um limitante superior para o passo de tempo quando atingir o estado estacionário.

Portanto, o GENSMAC é formulado como um método semi-implícito com passo temporal adaptativo. 


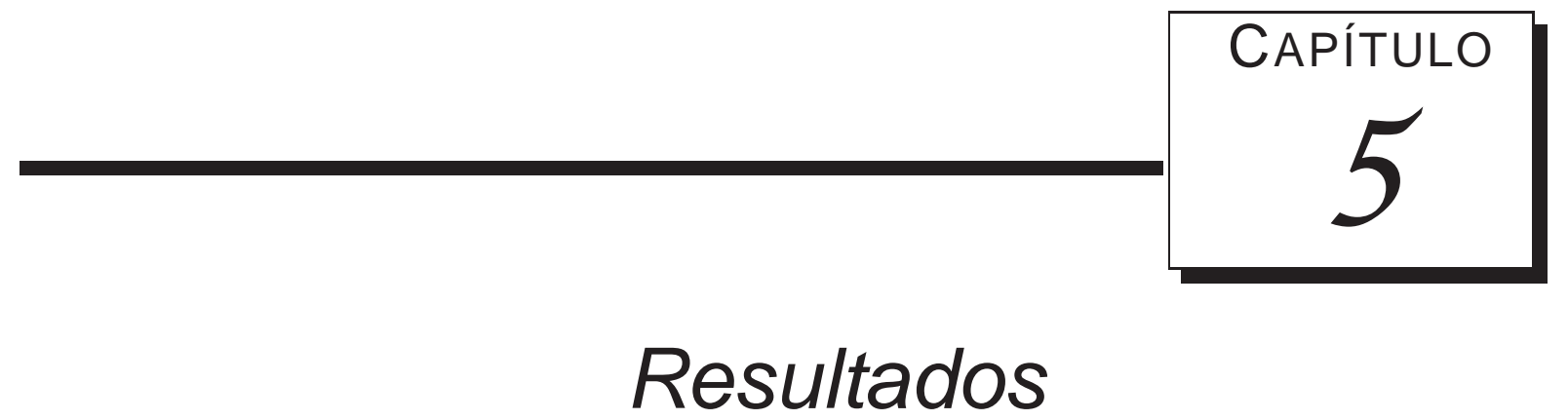

\subsection{Introdução}

Apresentamos no capítulo anterior, a metodologia para o cálculo do passo temporal adaptativo, que possibilita o aumento do passo de tempo em relação ao da FE. Neste capítulo, serão apresentados uma série de simulações com problemas clássicos $2 D$ que buscam demonstrar que é possível ter um passo de tempo maior que o da $\mathrm{FE}$, sendo este, baseado em propriedades do escoamento que vão sendo calculadas ao longo da simulação.

Os parâmetros utilizados para o pré-condicionador SOR serão os mesmos considerados em [MF09], uma vez que vários testes foram feitos para encontrar o melhor valor.

Em relação a solução de referência poderíamos considerar a solução obtida da FE, mas neste caso, o cálculo do erro não poderia ser feito por (4.16). Este erro é calculado utilizando-se $\mathrm{CN}$ e $\mathrm{AB}$, ambos métodos de segunda ordem, enquanto que na FE utiliza-se o método de Euler Explícito (primeira ordem) para integração temporal e assim uma nova estimativa para o cálculo do erro deveria ser feita, mas como $\mathrm{AB}$ é de segunda ordem, não teríamos como formular tal expressão. Consequentemente, embora o método implícito Crank-Nicolson esteja sendo usado na discretização temporal da equação de momento, será considerada como referência a solução numérica ao utilizar o passo de tempo fixo determinado pela restrição parabólica da FE, $\Delta t_{v i s c}$, pois este será considerado o pior caso para o passo de tempo. Assim para mostrar a eficiência do passo temporal adaptativo, dentre os diversos valores fixos para $\Delta t$ simulados, somente dois serão considerados: $\Delta t_{\text {visc }}$ e o passo de tempo utilizado na FI dado em [MF09] que utiliza (3.21) considerando $F_{\text {visc }}>1$.

Todos os resultados apresentados são expressos em variáveis adimensionais, sendo as variáveis dimensionais utilizadas somente na definição do problema. Além disso, para a análise de tempo de processamento e a fim de que os tempos de CPU fossem os mais fiéis possíveis, as simulações foram 
executadas no cluster do Laboratório de Matemática Aplicada e Computação Científica (LMACC), sempre em regime de uma simulação por processador. Todas as simulações foram executadas em máquinas $8 \times$ Intel Xeon E5345 de $2.33 \mathrm{GHz}$ com 16GB RAM. O tempo de processamento é expresso em d:h:min:s.

\subsection{Verificação do método numérico}

Para a verificação do método de passo temporal adaptativo, dois problemas foram escolhidos; um escoamento confinado, contração planar $4: 1$, e um escoamento com superfície livre, o chamado fountain flow. O primeiro tem o objetivo de ilustrar a metodologia presente em [KD10], ou seja, à medida que o tempo aumenta, o passo de tempo $\Delta t$ também aumenta. E o segundo tem por objetivo a validação do código. No estado estacionário, o problema fountain flow comporta-se como o problema poiseuille flow que possui solução exata, sendo portanto, possível validar (parcialmente) o código. Além disso, pretende-se mostrar a eficiência do método de passo temporal adaptativo para escoamentos com superfícies livres.

\subsubsection{Contração planar 4:1}

Consideramos o problema da contração planar $4: 1$, como na Figura 5.1. Os dados que definem o modelo são os seguintes:

- Domínio espacial: $0.3075 m \times 0.0875 m$.

- Diâmetro do inflow: $8.0 L_{0}=8.0 \times 10^{-2} \mathrm{~m}$.

- Diâmetro do outflow: $2.0 L_{0} m$.

- Velocidade no inflow: $U_{0}=1.0 \mathrm{~m} / \mathrm{s}$, com perfil de injeção parabólico.

- Comprimento do canal inicial: $15.0 L_{0} m$.

- Comprimento do canal final: $15.0 L_{0} m$.

- Distância entre inflow e outflow: $30.0 L_{0} m$.

- Campo gravitacional: $g_{0}=9.81 \mathrm{~m} / \mathrm{s}^{2}, g^{x}=0.0$ e $g^{y}=0.0$.

- Viscosidade: $\nu=0.2 \mathrm{~m}^{2} / \mathrm{s}$.

- Parâmetros adimensionais: $R e=0.05, F r \approx 3.19275$.

- Discretização do domínio espacial: $246 \times 70$ células nas direções $x$ e $y$, respectivamente.

- Passos adimensionais: $\Delta m=0.125, \Delta t_{\text {visc }}=1.953125 \times 10^{-4}$.

- Tempo final: $t_{f}=1.0 \times 10^{-2} s$. 
- Parâmetros do pré-condicionador SOR: $\omega=1.4$ na equação do momento e $\omega=1.8$ na equação de Poisson.

- Tolerância para o cálculo do erro $\left\|\mathbf{e}^{n}\right\|: \varepsilon=1.0 \times 10^{-4}$.

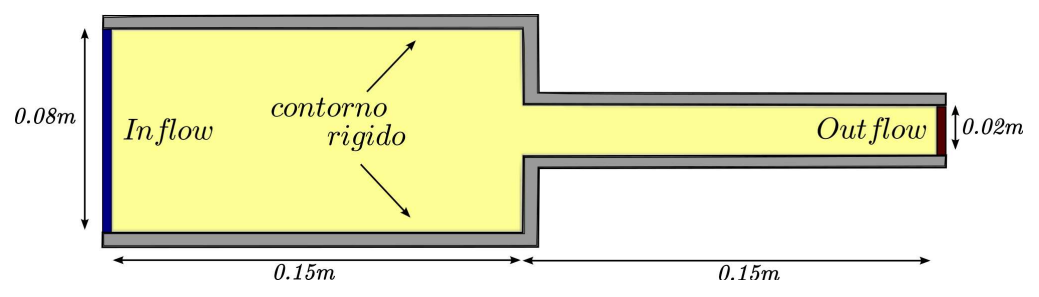

Figura 5.1: Ilustração do domínio para simulação da contração planar $4: 1$.

A motivação para a escolha deste modelo é por este representar um escoamento confinado. Sendo assim, é possível mostrar que o passo de tempo aumenta com o tempo, e quando no estado estacionário a condição $C F L$ é um limitante superior, não permitindo o crescimento do passo de tempo. Isto pode ser observado na Figura 5.2 que apresenta os valores do passo temporal adaptativo.

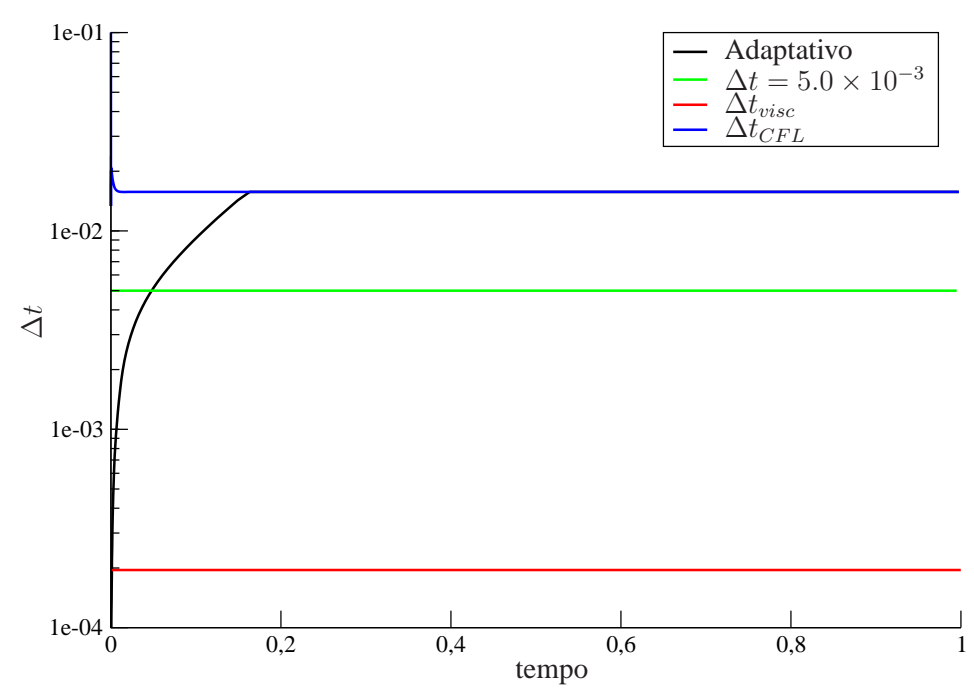

Figura 5.2: Valores do passo temporal usados para a simulação da contração planar 4 : 1 , considerando $\Delta m=0.125$.

Na Figura 5.3 apresentamos uma comparação entre o valor do erro $\left\|\mathbf{e}^{n}\right\|$ para o passo temporal adaptativo e os dois casos com passo fixo, $\Delta t_{v i s c}=1.953125 \times 10^{-4}$ e $\Delta t=5.0 \times 10^{-3}\left(F_{v i s c}=25.6\right)$. Analisando a solução para alguns tempos, observa-se que o método com passo temporal adaptativo atinge o estado estacionário em $t \approx 3.365 \times 10^{-1}$, o passo fixo $\Delta t=5.0 \times 10^{-3} \mathrm{em} t \approx 4.150 \times 10^{-1}$ e $\Delta t_{v i s c}$ em $t \approx 3.461 \times 10^{-1}$. Assim, observa-se que o método com passo temporal adaptativo é mais preciso que o de passo fixo $\Delta t=5.0 \times 10^{-3}$, pois antes do estado estacionário ser atingido $\left(t \approx 3.4 \times 10^{-1}\right)$, o erro para o passo temporal adaptativo é menor. Em relação ao de passo fixo $\Delta t_{v i s c}$ 
era esperado um erro bem menor, pois o passo de tempo utilizado é muito pequeno. Assim, o método com passo temporal adaptativo se mostra uma boa alternativa em termos de precisão dos resultados.

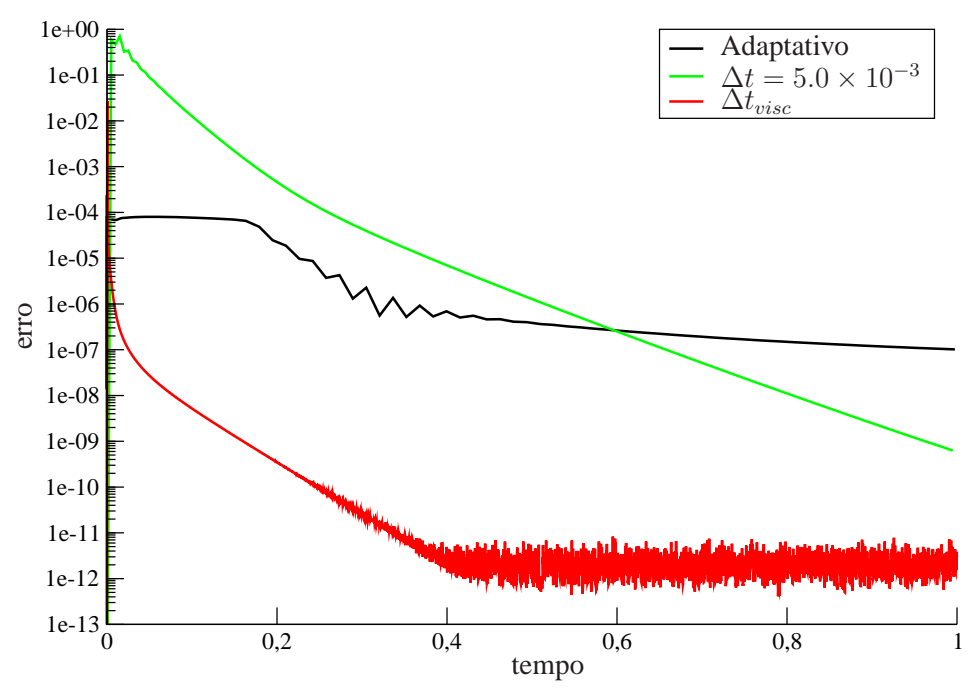

Figura 5.3: Comparação entre o valor do erro $\left\|\mathbf{e}^{n}\right\|$ para o passo temporal adaptativo e dois casos com passo fixo obtidos na simulação da contração planar $4: 1$.

Além de precisão, o passo temporal adaptativo proporciona um ganho significativo em termos de tempo de simulação. A Tabela 5.1 ilustra o tempo de CPU utilizado para obter a solução em $t=1.0$. A utilização do passo temporal adaptativo proporcionou um ganho de, aproximadamente, $95 \%$ em tempo de CPU em relação ao passo fixo $\Delta t_{v i s c}$. Para este problema, ocorrem duas reduções nos ciclos iniciais, o que permitiu nos próximos ciclos um passo de tempo cada vez maior.

\begin{tabular}{lcc}
\hline \hline Passo de tempo & Tempo de CPU & No. Ciclos Computacionais \\
\hline \hline Adaptativo & $00: 00: 00: 15$ & 112 \\
$\Delta t=5.0 \times 10^{-3}$ & $00: 00: 00: 20$ & 200 \\
$\Delta t_{v i s c}=1.953125 \times 10^{-4}$ & $00: 00: 05: 09$ & 5120 \\
\hline \hline
\end{tabular}

Tabela 5.1: Tempo de processamento para a simulação da contração planar $4: 1$ até $t=1.0$.

Por fim, na Figura 5.4 temos a evolução da contração planar $4: 1$ usando o passo temporal adaptativo. Estão representados a pressão, o perfil de velocidade em $x$ e $y$, respectivamente. Apresentamos o comportamento da solução transiente até atingir o estado estacionário em $t \approx 3.365 \times 10^{-1}$.

Portanto, o método implementado está de acordo com o proposto em [KD10]. Além disso, um passo de tempo, que garante uma precisão pré-fixada e redução do custo computacional, maior que o utilizado até então na FE do GENSMAC é possível e mais preciso em relação ao passo de tempo calculado na FI que utiliza (3.21) com $F_{\text {visc }}>1$. 

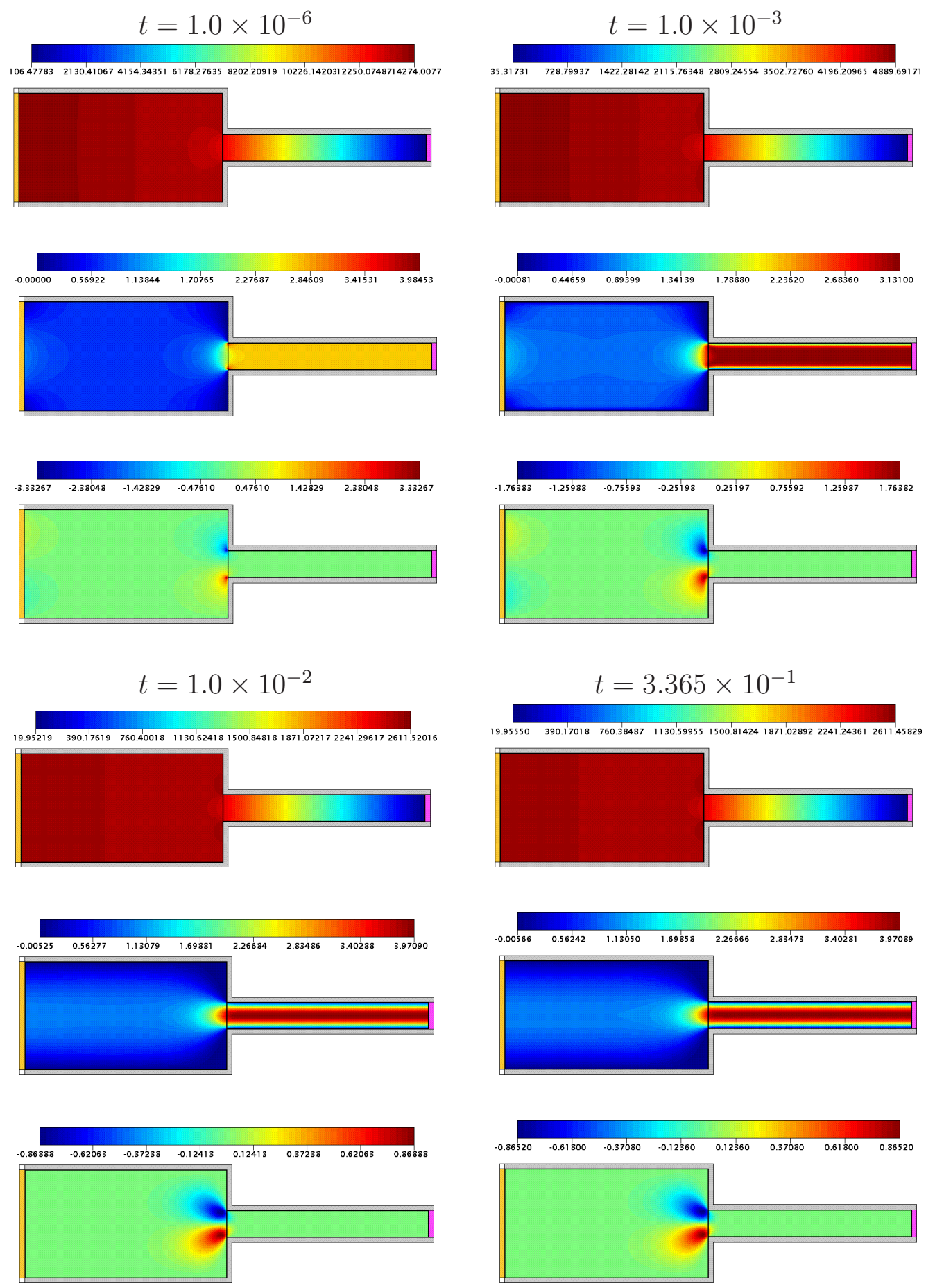

Figura 5.4: Evolução da contração planar $4: 1(R e=0.05)$ utilizando o passo temporal adaptativo. Na figura estão representados os resultados numéricos para pressão, perfil de velocidade em $x$ e $y$, respectivamente. Em $t \approx 3.365 \times 10^{-1}$ o fluido atinge o estado estacionário. 


\subsubsection{Poiseuille flow e Fountain flow}

Para testar o método numérico, inicialmente, consideramos um escoamento em um canal de largura $L$ e comprimento 5.0 L, conhecido como poiseuille flow, ilustrado na Figura 5.5. Neste escoamento, o canal inicialmente está cheio, caracterizando um escoamento confinado.

Esta escolha é motivada pelo fato deste problema possuir solução exata, sendo portanto, utilizado para validar o código. Os dados que definem o modelo são os seguintes:

- Domínio espacial: $5.15 m \times 1.15 m$.

- Diâmetro do outflow: $L_{0}=1.0 \mathrm{~m}$.

- Comprimento do canal: $5.0 L_{0} m$.

- Campo gravitacional: $g_{0}=9.81 \mathrm{~m} / \mathrm{s}^{2}, g^{x}=1.0 \mathrm{e} g^{y}=0.0$.

- Viscosidade: $\nu=10.0 \mathrm{~m}^{2} / \mathrm{s}$.

- Parâmetros adimensionais: $R e=0.1, F r \approx 0.319275$.

- Discretização do domínio espacial: 206 × 46 células nas direções $x$ e $y$, respectivamente.

- Tempo final: $t_{f}=10.0 \mathrm{~s}$.

- Parâmetros do pré-condicionador SOR: $\omega=1.6$ na equação do momento e $\omega=1.8$ na equação de Poisson.

- Tolerância para o cálculo do erro $\left\|\mathbf{e}^{n}\right\|: \varepsilon=1.0 \times 10^{-5}$.

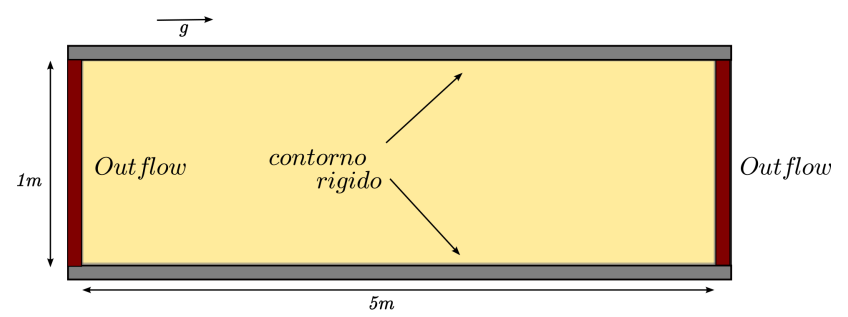

Figura 5.5: Ilustração do domínio para simulação do poiseuille flow. Coloca-se outflow nas duas extremidades para representar a condição de Neumann no contorno.

A solução exata para o comportamento transiente do modelo é conhecida, sendo obtida pela aplicação da transformada de Laplace ([MF97]) e dada por

$$
u(x, y, t)=-\frac{F}{2 \nu} y(y-L)-\sum_{n=0}^{\infty} \frac{4 F L^{2}}{\nu \pi^{3}(2 n+1)^{3}} \sin \left(\frac{\pi y}{L}(2 n+1)\right) \exp \left(-\frac{(2 n+1)^{2} \pi^{2} \nu}{L^{2}} t\right)
$$


onde $x$ é a coordenada na direção do escoamento, $y$ é a coordenada na direção normal ao canal e $F$ é uma força aplicada paralela ao eixo $x$ para $t \geq 0$. Neste modelo, usa-se a componente na direção $x$ do campo gravitacional $\mathrm{g}$, como valor para $F$.

A Figura 5.6 apresenta uma comparação entre o perfil de velocidade numérica transiente $\mathbf{u}^{n}$ e a solução exata (5.1), no ponto $x=2.5 L_{0}$ do canal, considerando-se 1000 termos na série (5.1). Pode-se verificar nesta figura que nos tempos iniciais, as soluções apresentam pequenas discrepâncias que desaparecem no estado estacionário, evidenciando, portanto, que a metodologia foi implementada de forma correta. Ainda, para conseguir captar a solução transiente nos tempos iniciais, foi necessário utilizar uma tolerância menor para o cálculo do erro, considerando assim, $\varepsilon=1.0 \times 10^{-5}$.

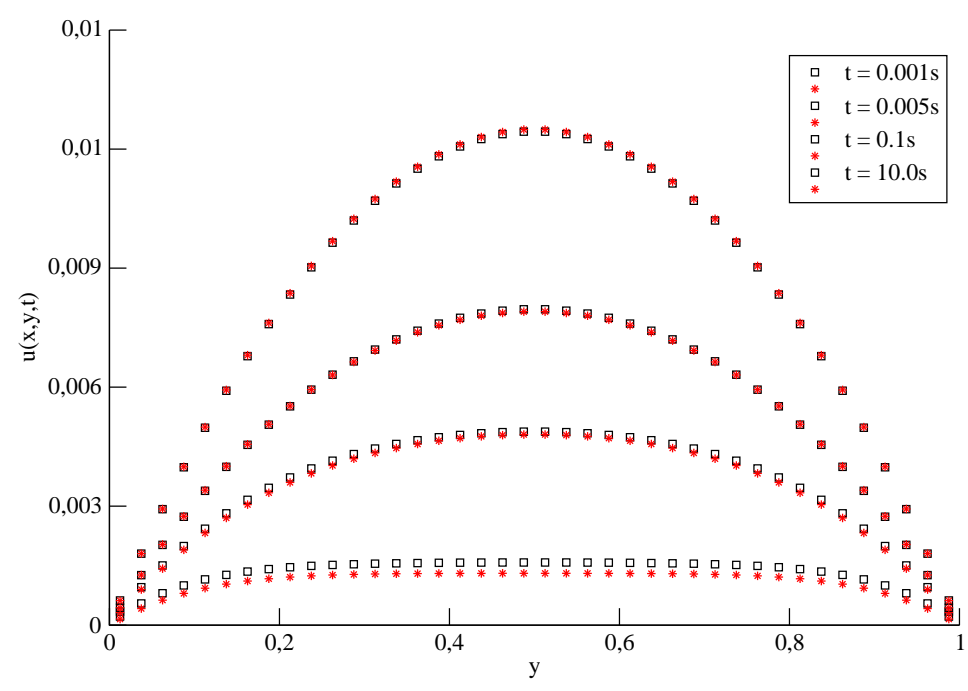

Figura 5.6: Comparação entre a solução exata $\square$ e a solução numérica * para o escoamento poiseuille flow em diferentes tempos usando o passo temporal adaptativo, no ponto $x=2.5 L_{0}$ do canal.

Uma vez verificado para um escoamento confinado, também se faz necessário a verificação para um escoamento com superfícies livres, mas nestes casos, a solução exata não é conhecida. Desta forma, consideramos outro escoamento em um canal. Inicialmente o canal está vazio e injeta-se fluido na região de entrada com um perfil de velocidade parabólico, até que o escoamento atinja o estado estacionário, caracterizando o fountain flow, ilustrado na Figura 5.7. Ao atingir o estado estacionário, a solução numérica do fountain flow se comporta como a solução do poiseuille flow, sendo possível assim, utilizar (5.1) como solução exata para o fountain flow e verificar se a solução numérica está em concordância com a solução exata.

Os dados que definem o modelo são os seguintes:

- Domínio espacial: $5.15 m \times 1.15 m$.

- Diâmetro do inflow: $L_{0}=1.0 \mathrm{~m}$.

- Diâmetro do outflow: $L_{0} m$. 
- Velocidade no inflow: $U_{0}=1.0 \mathrm{~m} / \mathrm{s}$, com perfil de injeção parabólico.

- Comprimento do canal: $5.0 L_{0} m$.

- Campo gravitacional: $g_{0}=9.81 \mathrm{~m} / \mathrm{s}^{2}, g^{x}=0.0$ e $g^{y}=0.0$.

- Viscosidade: $\nu=10.0 \mathrm{~m}^{2} / \mathrm{s}$.

- Parâmetros adimensionais: $R e=0.1, F r \approx 0.319275$.

- Discretização do domínio espacial: 206 × 46 células nas direções $x$ e $y$, respectivamente.

- Passos adimensionais: $\Delta m=0.025, \Delta t_{\text {visc }}=1.5625 \times 10^{-5}$.

- Tempo final: $t_{f}=20.0 s$.

- Parâmetros do pré-condicionador SOR: $\omega=1.6$ na equação do momento e $\omega=1.8$ na equação de Poisson.

- Tolerância para o cálculo do erro $\left\|\mathrm{e}^{n}\right\|: \varepsilon=1.0 \times 10^{-4}$.

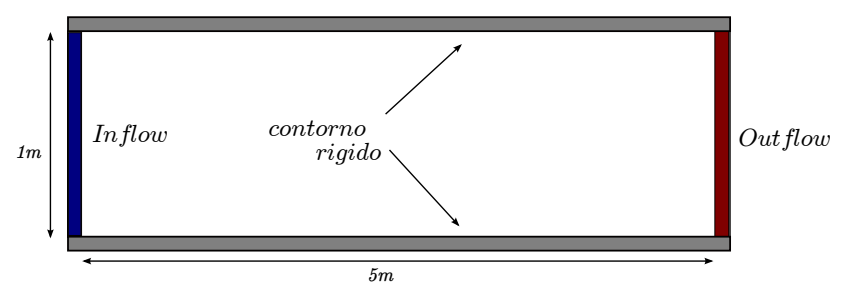

Figura 5.7: Ilustração do domínio para simulação do foutain flow.

Nas figuras 5.8 e 5.9 uma análise do comportamento da simulação é mostrada no decorrer de 20.0s. Na primeira delas, apresentamos os valores do passo temporal adaptativo. A curva foi suavizada tomando-se a média dos 500 pontos vizinhos para uma melhor visualização do comportamento do passo de tempo. Além disso, para este modelo, temos que o estado estacionário é atingido em $t \approx 11.6$ ao utilizar o passo temporal adaptativo e o passo fixo $\Delta t_{\text {visc }}$ enquanto que para o passo fixo $\Delta t=1.0 \times 10^{-3}$ em $t \approx 9.92$. Deste modo, o passo de tempo matém um certo perfil até $t \approx 7.0$ onde atinge-se o outflow e, nesta fase, oscilações mais acentuadas são observadas no passo de tempo que desaparecem no estado estacionário a partir de $t \approx 11.6$. Assim, o passo de tempo passa a ser limitado pela condição $C F L$, ocasionando um passo de tempo constante.

Na Figura 5.9 apresentamos uma comparação entre o valor do erro $\left\|\mathbf{e}^{n}\right\|$ para o passo adaptativo e os dois casos com passo fixo, $\Delta t_{\text {visc }}=1.5625 \times 10^{-5} \mathrm{e} \Delta t=1.0 \times 10^{-3}\left(F_{\text {visc }}=64.0\right)$. Novamente, observa-se que o método com passo temporal adaptativo é mais preciso que o de passo fixo $\Delta t=$ $1.0 \times 10^{-3}$, pois com o passo temporal adaptativo consegue-se manter $\left\|\mathbf{e}^{n}\right\| \leq 1.0 \times 10^{-4}\left(\frac{1}{0.7}\right)^{1 / 3}$ 


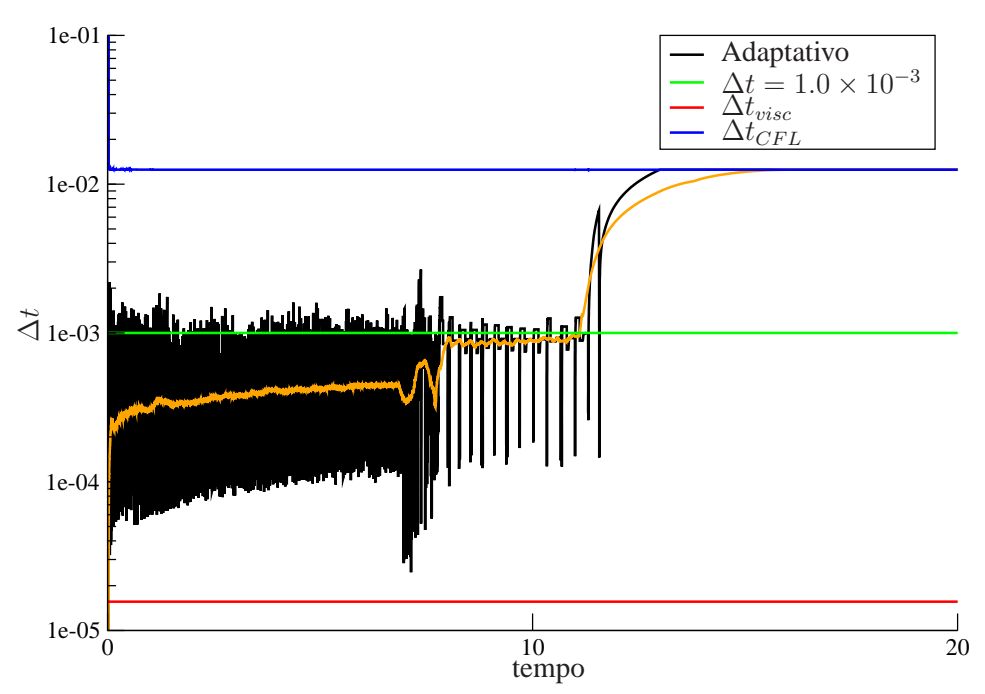

Figura 5.8: Valores do passo temporal usados na simulação do fountain flow, considerando $\Delta m=$ 0.025. Em laranja, a curva do passo temporal adaptativo foi suavizada tomando-se a média dos 500 pontos vizinhos.

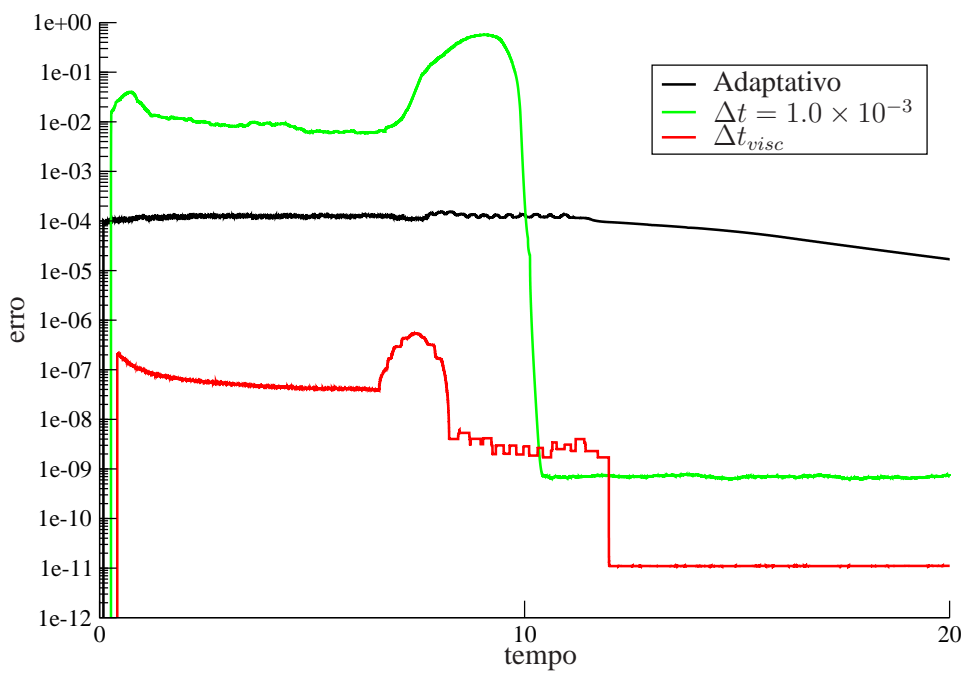

Figura 5.9: Comparação entre o valor do erro $\left\|\mathrm{e}^{n}\right\|$ para o passo temporal adaptativo e dois casos com passo fixo obtidos na simulação do Fountain Flow. As curvas foram suavizadas tomando-se a média dos 500 pontos vizinhos.

antes do estado estacionário ser atingido $(t \approx 11.6)$. Desta forma, o passo temporal adaptativo segue a física do problema e garante precisão dos resultados.

Em termos de tempo de CPU, o passo temporal adaptativo também é melhor como ilustrado na Tabela 5.2 que mostra um ganho significativo, de aproximadamente $97 \%$, no tempo de simulação. E, 
para este problema é interessante ressaltar que na simulação $\Delta t$ permanece igual a $\Delta t_{0}=1.0 \times 10^{-6}$ durante muitos ciclos computacionais $(\approx 25000)$, pois o erro $\left\|\mathbf{e}^{n}\right\|$ só é calculado quando se tem células do tipo $\mathbf{F}$, e portanto poderia se esperar nenhum ganho em tempo de simulação, mas nos próximos ciclos $\Delta t$ aumenta para $O\left(10^{-4}\right)$ o que possibilitou o ganho observado na tabela. Portanto, podemos concluir que é possível utilizar um passo de tempo maior que aquele da FE do GENSMAC e ao mesmo tempo mais preciso em relação a FI (que considera $F_{v i s c}>1$ ) que garante precisão e redução do custo computacional.

\begin{tabular}{lcc}
\hline \hline Passo de tempo & Tempo de CPU & No. Ciclos Computacionais \\
\hline \hline Adaptativo & $00: 00: 22: 59$ & 50401 \\
$\Delta t=1.0 \times 10^{-3}$ & $00: 00: 16: 40$ & 20000 \\
$\Delta t_{\text {visc }}=1.5625 \times 10^{-5}$ & $00: 13: 40: 12$ & 1280000 \\
\hline \hline
\end{tabular}

Tabela 5.2: Tempo de processamento para a simulação do fountain flow até $t=20.0$.

A validação (parcial) do código é feita pela comparação dos resultados da simulação do fountain flow no estado estacionário com a solução exata do poiseuille flow. Assim, a Tabela 5.3 apresenta os valores obtidos na simulação do fountain flow ao atingir o estado estacionário em $t \approx 11.6$, no ponto $x=2.5 L_{0}$ do canal. Estão representados a solução numérica $\mathbf{u}^{n}$, a solução exata $u(x, y, t)$ dada em (5.1) e o |erro| entre ambas. Pela análise do |erro| é possível observar que os valores obtidos na simulação estão próximos da solução exata, sendo possível assim, garantir que o código fornece uma boa margem de segurança nos resultados.

Por fim, na Figura 5.10 temos a evolução do fountain flow usando o passo temporal adaptativo. Estão representados a pressão, o perfil de velocidade em $x$ e $y$, respectivamente. O fluido entra no canal com um perfil parabólico e atinge o outflow em $t \approx 7.0$, explicando a flutuação no passo de tempo visto na Figura 5.8. E, no tempo $t \approx 11.64$ atinge o estado estacionário, possibilitando o aumento do passo de tempo que passa a ser limitado pela condição $C F L$.

Portanto, o método numérico está verificado e, assim, podemos simular escoamentos com superfícies livres usando um passo temporal adaptativo.

\subsection{Aplicações}

Motivados pelo bom desempenho do método com passo temporal adaptativo, dois problemas com superfícies livres são escolhidos: inchamento do extrudado e jet flow.

\subsubsection{Inchamento do extrudado}

O inchamento do extrudado de um fluido viscoso newtoniano é um problema com superfícies livres muito conhecido na literatura. O escoamento consiste na extrusão do fluido a partir de um canal inicial de placas paralelas, como pode ser visto na Figura 5.11, e para baixo número de Reynolds, o fluido tende a inchar quando sai do canal e entra em contato com a atmosfera.

Os dados que definem o modelo são os seguintes: 


\begin{tabular}{cccc}
\hline \hline$y$ & $\mathrm{u}^{n}$ & $u(x, y, t)$ & $\mid$ erro $\mid$ \\
\hline \hline $1.25 \mathrm{e}-02$ & $4.961928 \mathrm{e}-02$ & $4.937500 \mathrm{e}-02$ & $2.442754 \mathrm{e}-04$ \\
$6.25 \mathrm{e}-02$ & $2.343470 \mathrm{e}-01$ & $2.343750 \mathrm{e}-01$ & $2.796864 \mathrm{e}-05$ \\
$1.125 \mathrm{e}-01$ & $3.993446 \mathrm{e}-01$ & $3.993750 \mathrm{e}-01$ & $3.036297 \mathrm{e}-05$ \\
$1.625 \mathrm{e}-01$ & $5.443547 \mathrm{e}-01$ & $5.443750 \mathrm{e}-01$ & $2.032499 \mathrm{e}-05$ \\
$2.125 \mathrm{e}-01$ & $6.693606 \mathrm{e}-01$ & $6.693750 \mathrm{e}-01$ & $1.442223 \mathrm{e}-05$ \\
$2.625 \mathrm{e}-01$ & $7.743638 \mathrm{e}-01$ & $7.743750 \mathrm{e}-01$ & $1.124744 \mathrm{e}-05$ \\
$3.125 \mathrm{e}-01$ & $8.593655 \mathrm{e}-01$ & $8.593750 \mathrm{e}-01$ & $9.480779 \mathrm{e}-06$ \\
$3.625 \mathrm{e}-01$ & $9.243665 \mathrm{e}-01$ & $9.243750 \mathrm{e}-01$ & $8.469321 \mathrm{e}-06$ \\
$4.125 \mathrm{e}-01$ & $9.693671 \mathrm{e}-01$ & $9.693750 \mathrm{e}-01$ & $7.900888 \mathrm{e}-06$ \\
$4.625 \mathrm{e}-01$ & $9.943674 \mathrm{e}-01$ & $9.943750 \mathrm{e}-01$ & $7.623332 \mathrm{e}-06$ \\
$5.375 \mathrm{e}-01$ & $9.943674 \mathrm{e}-01$ & $9.943750 \mathrm{e}-01$ & $7.624542 \mathrm{e}-06$ \\
$5.875 \mathrm{e}-01$ & $9.693671 \mathrm{e}-01$ & $9.693750 \mathrm{e}-01$ & $7.900932 \mathrm{e}-06$ \\
$6.375 \mathrm{e}-01$ & $9.243665 \mathrm{e}-01$ & $9.243750 \mathrm{e}-01$ & $8.469231 \mathrm{e}-06$ \\
$6.875 \mathrm{e}-01$ & $8.593655 \mathrm{e}-01$ & $8.593750 \mathrm{e}-01$ & $9.480298 \mathrm{e}-06$ \\
$7.375 \mathrm{e}-01$ & $7.743638 \mathrm{e}-01$ & $7.743750 \mathrm{e}-01$ & $1.124705 \mathrm{e}-05$ \\
$7.875 \mathrm{e}-01$ & $6.693606 \mathrm{e}-01$ & $6.693750 \mathrm{e}-01$ & $1.442164 \mathrm{e}-05$ \\
$8.375 \mathrm{e}-01$ & $5.443547 \mathrm{e}-01$ & $5.443750 \mathrm{e}-01$ & $2.032448 \mathrm{e}-05$ \\
$8.875 \mathrm{e}-01$ & $3.993446 \mathrm{e}-01$ & $3.993750 \mathrm{e}-01$ & $3.036251 \mathrm{e}-05$ \\
$9.375 \mathrm{e}-01$ & $2.343470 \mathrm{e}-01$ & $2.343750 \mathrm{e}-01$ & $2.796763 \mathrm{e}-05$ \\
$9.875 \mathrm{e}-01$ & $4.961929 \mathrm{e}-02$ & $4.937500 \mathrm{e}-02$ & $2.442885 \mathrm{e}-04$ \\
\hline \hline
\end{tabular}

Tabela 5.3: Valores para a solução numérica $\mathbf{u}^{n}$, a solução exata $u(x, y, t)$ e o $\mid$ erro $\mid$ no ponto $x=$ $2.5 L_{0}$ do canal em $t=11.64$.

- Domínio espacial: $15.15 m \times 3.0 m$.

- Diâmetro do inflow: $L_{0}=1.0 \mathrm{~m}$.

- Diâmetro do outflow: $3.0 L_{0} m$.

- Velocidade no inflow: $U_{0}=1.0 \mathrm{~m} / \mathrm{s}$, com perfil de injeção reto.

- Comprimento do canal inicial: $5.0 L_{0} m$.

- Distância entre inflow e outflow: $15.0 L_{0} m$.

- Campo gravitacional: $g_{0}=9.81 \mathrm{~m} / \mathrm{s}^{2}, g^{x}=0.0$ e $g^{y}=0.0$.

- Viscosidade: $\nu=10.0 \mathrm{~m}^{2} / \mathrm{s}$.

- Parâmetros adimensionais: $R e=0.1, F r \approx 0.319275$.

- Discretização do domínio espacial: 606 × 120 células nas direções $x$ e $y$, respectivamente.

- Passos adimensionais: $\Delta m=0.025, \Delta t_{\text {visc }}=1.5625 \times 10^{-5}$. 


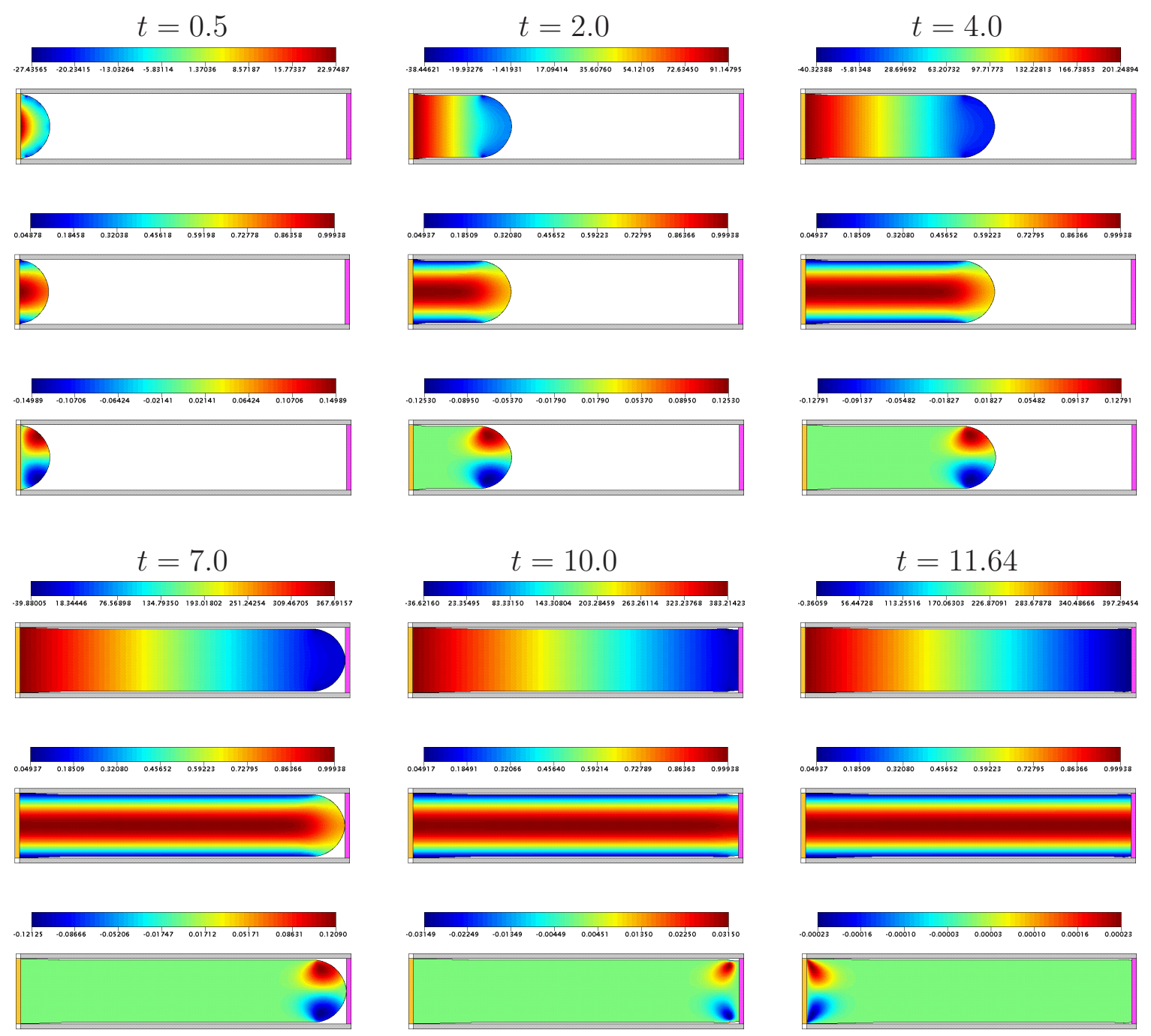

Figura 5.10: Evolução do fountain flow $(R e=0.1)$ utilizando o passo temporal adaptativo. Na figura estão representados os resultados numéricos para pressão, perfil de velocidade em $x$ e $y$, respectivamente. Em $t \approx 7.0$ o fluido chega ao outflow e em $t \approx 11.64$ atinge o estado estacionário.

- Tempo final: $t_{f}=45.0 \mathrm{~s}$.

- Parâmetros do pré-condicionador SOR: $\omega=1.4$ na equação do momento e $\omega=1.8$ na equação de Poisson.

- Tolerância para o cálculo do erro $\left\|\mathbf{e}^{n}\right\|: \varepsilon=1.0 \times 10^{-4}$.

Este problema tem um carácter interessante, pois é possível identificar três fases do escoamento através do gráfico do passo de tempo, em [KD10] esse fato é observado ao simular o escoamento em um canal retangular com uma obstrução cilíndrica de diâmetro unitário.

Nas figuras 5.12 e 5.13 uma análise do comportamento da simulação é mostrada no decorrer de 45.0s. Na primeira delas, apresentamos os valores do passo temporal adaptativo. Novamente, a 


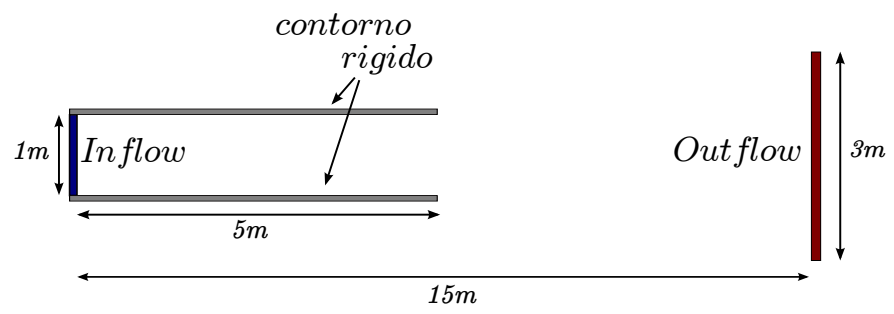

Figura 5.11: Ilustração do domínio para simulação do inchamento do extrudado.

curva foi suavizada tomando-se a média dos 500 pontos vizinhos. Deste modo, antes do fluido sair do canal em $t \approx 4.5$ um aumento considerável no passo de tempo é observado e este, decai após o fuido deixar o canal devido à presença da superfície livre, já em $t \approx 16.0$ o fluido atinge o outflow, no gráfico percebe-se um decaimento no passo de tempo, que continua a oscilar até $t \approx 33.0$, onde atinge-se o estado estacionário. Assim, o passo de tempo aumenta até ser limitado pela condição $C F L$ continuando constante até o fim da simulação.

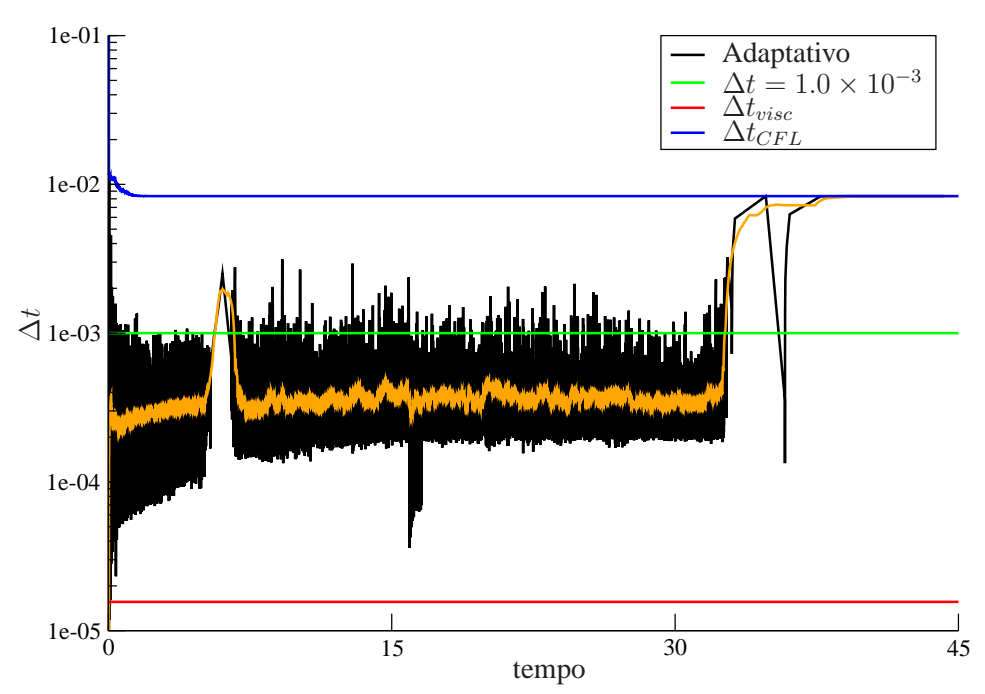

Figura 5.12: Valores do passo temporal usados na simulação do inchamento do extrudado, considerando $\Delta m=0.025$. Em laranja, a curva do passo temporal adaptativo foi suavizada tomando-se a média dos 500 pontos vizinhos.

Na Figura 5.13 apresentamos uma comparação entre o valor do $\left\|\mathbf{e}^{n}\right\|$ para o passo adaptativo e os dois casos com passo fixo, $\Delta t_{v i s c}=1.5625 \times 10^{-5}$ e $\Delta t=1.0 \times 10^{-3}\left(F_{v i s c}=64.0\right)$. Observa-se, novamente, que o método com passo temporal adaptativo é mais preciso que o de passo fixo $\Delta t=$ $1.0 \times 10^{-3}$ e em ambos, o erro tende a zero no estado estacionário. Desta forma, o método com passo temporal adaptativo, mais uma vez, se mostra uma boa alternativa em termos de precisão dos resultados. 


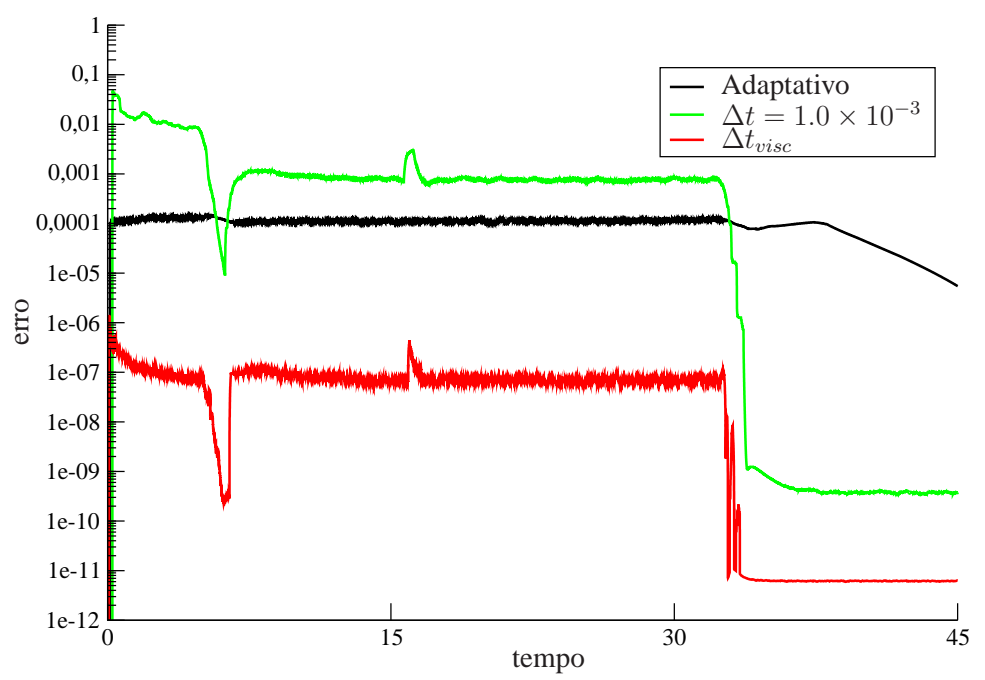

Figura 5.13: Comparação entre o valor do erro $\left\|\mathrm{e}^{n}\right\|$ para o passo temporal adaptativo e dois casos com passo fixo obtidos na simulação do inchamento do extrudado. As curvas foram suavizadas tomando-se a média dos 500 pontos vizinhos.

Em termos de tempo de CPU, como é ilustrado na Tabela 5.4, o passo temporal adaptativo se mostrou pior do que o passo fixo $\Delta t=1.0 \times 10^{-3}$, gastando mais que o dobro de tempo de processamento. Mas um método precisa garantir precisão dos resultados e, como observado na Figura 5.13 o erro $\left\|\mathbf{e}^{n}\right\|$ para $\Delta t=1.0 \times 10^{-3}$ é maior, logo, o passo temporal adaptativo fornece valores para $\Delta t$ que garantem precisão. Além disso, ao comparar o passo temporal adaptativo com o passo fixo $\Delta t_{\text {visc }}$, o ganho no tempo de CPU é significativamente maior, um ganho de aproximadamente, $96 \%$ e, isso se deve ao fato da grande redução do número de ciclos computacionais, ou seja, mesmo com rejeições no passo de tempo, sendo necessário o recálculo da solução num mesmo ciclo, um ganho no tempo de simulação é possível. Portanto, o passo temporal adaptativo mais uma vez, se mostra eficiente tanto em precisão quanto em custo computacional.

\begin{tabular}{lcc}
\hline \hline Passo de tempo & Tempo de CPU & No. Ciclos Computacionais \\
\hline \hline Adaptativo & $00: 11: 22: 48$ & 117777 \\
$\Delta t=1.0 \times 10^{-3}$ & $00: 05: 52: 38$ & 45000 \\
$\Delta t_{\text {visc }}=1.5625 \times 10^{-5}$ & $13: 02: 20: 04$ & 2880000 \\
\hline \hline
\end{tabular}

Tabela 5.4: Tempo de processamento para a simulação do inchamento do extrudado até $t=45.0$.

Por fim, na Figura 5.14 temos a evolução do inchamento do extrudado usando o passo temporal adaptativo. Estão representados a pressão, o perfil de velocidade em $x$ e $y$, respectivamente. O fluido entra no canal com um perfil reto e desenvolve-se atingindo um perfil parabólico. Em $t \approx 4.5$ o fluido sai do canal, chegando no outflow em $t \approx 16.0$ e em $t \approx 33.0$ atinge o estado estacionário. 

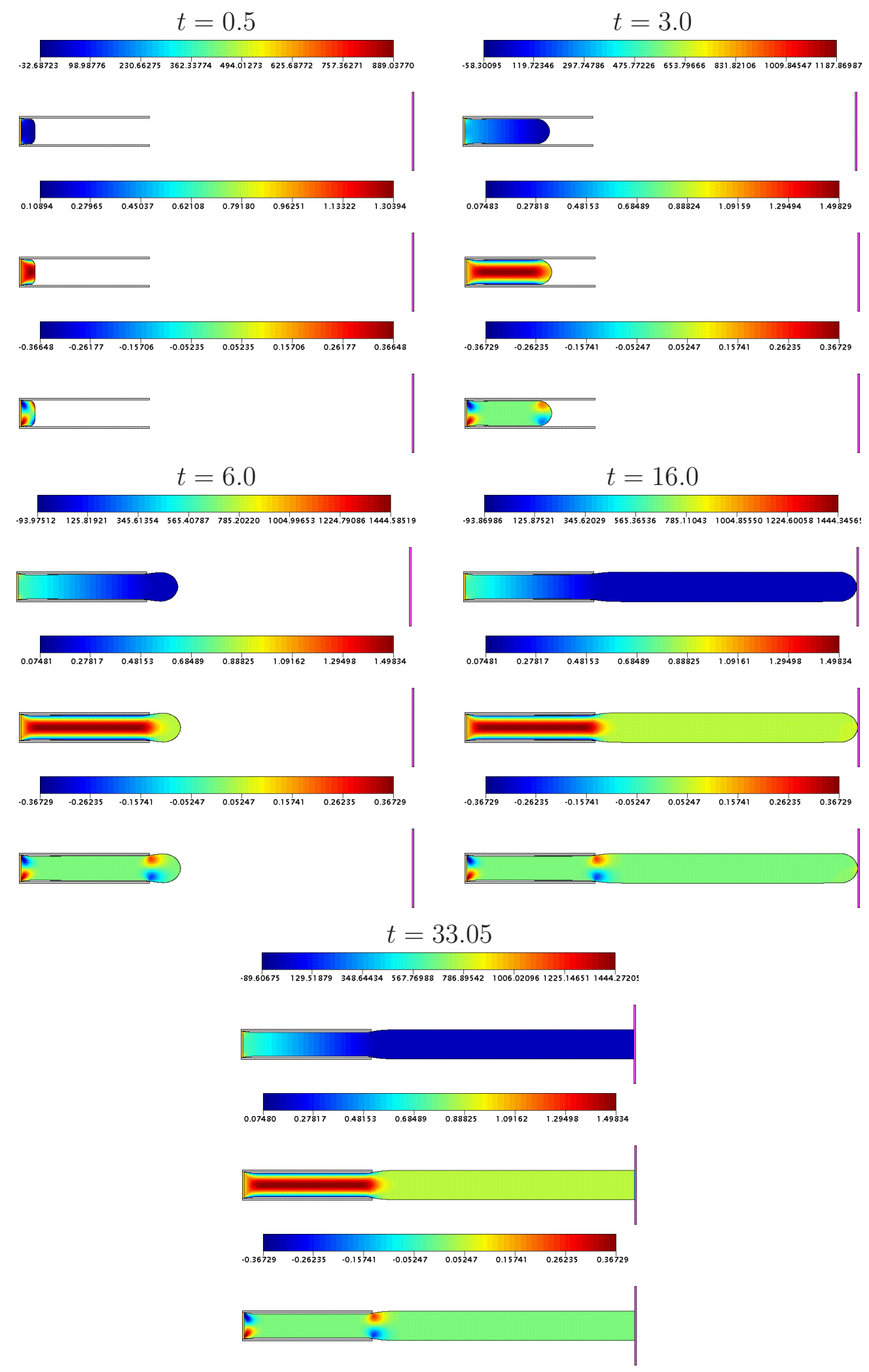

Figura 5.14: Evolução do inchamento do extrudado $(R e=0.1)$ utilizando o passo temporal adaptativo. Na figura estão representados os resultados numéricos para pressão, perfil de velocidade em $x \mathrm{e}$ $y$, respectivamente. Em $t \approx 4.5$ o fluido sai do canal, chegando no outflow em $t \approx 16.0$ e em $t \approx 33.0$ atinge o estado estacionário. 
Portanto, com esta simulação foi possível ter um ganho significativo em tempo de simulação e ainda garantir precisão dos resultados, mostrando mais uma vez, que o passo temporal adaptativo é uma boa escolha.

\subsubsection{Jet flow}

O Jet flow consiste em uma piscina de fluido inicialmente em repouso, que possui um inflow, do mesmo fluido, posicionado muito próximo à sua superfície livre, como na Figura 5.15, na qual os dados que definem o modelo são os seguintes:

- Domínio espacial: $0.123 m \times 0.173 m$.

- Diâmetro do inflow: $L_{0}=4.0 \times 10^{-3} \mathrm{~m}$.

- Velocidade no inflow: $U_{0}=0.5 \mathrm{~m} / \mathrm{s}$, com perfil de injeção reto.

- Altura do inflow ao fundo da caixa: $h_{1}=0.17 m$.

- Largura entre as duas paredes da caixa: $h_{2}=0.12 m$.

- Altura da superfície livre do fluido inicial ao fundo da caixa: $h_{3}=0.16 \mathrm{~m}$.

- Campo gravitacional: $g_{0}=9.81 \mathrm{~m} / \mathrm{s}^{2}, g^{x}=0.0$ e $g^{y}=-1.0$.

- Viscosidade: $\nu=1.0 \times 10^{-2} \mathrm{~m}^{2} / \mathrm{s}$.

- Parâmetros adimensionais: $R e=0.2, F r \approx 2.524094$.

- Discretização do domínio espacial: $246 \times 346$ células nas direções $x$ e $y$, respectivamente.

- Passos adimensionais: $\Delta m=0.125, \Delta t_{\text {visc }}=7.8125 \times 10^{-4}$.

- Tempo final: $t_{f}=0.64 s$.

- Parâmetros do pré-condicionador SOR: $\omega=1.4$ na equação do momento e $\omega=1.8$ na equação de Poisson.

- Tolerância para o cálculo do erro $\left\|\mathbf{e}^{n}\right\|: \varepsilon=1.0 \times 10^{-4}$.

A motivação para o estudo deste modelo é o fato dele possuir a componente $g^{y}$ do campo gravitacional diferente de zero, $g^{y}=-1.0$, além de resultar em um problema de grande porte em termos computacionais. Além disso, para problemas deste tipo, em que uma grande quantidade de fluido inicialmente está em repouso, a fórmula (4.18) não é uma boa escolha para o cálculo da norma do erro, pois fornece um erro muito pequeno, e com isso, o passo de tempo aumenta consideravelmente no início da simulação, fornecendo uma solução numérica diferente da esperada. Logo, para problemas deste tipo, calcula-se a norma do erro, usando a norma do máximo, 


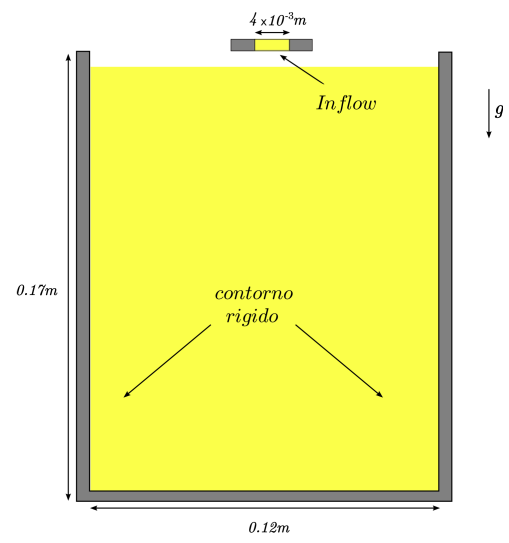

Figura 5.15: Ilustração do domínio para simulação do jet flow.

$$
\left\|\mathbf{e}^{n}\right\|_{\infty}=\max \left\{\max \left|e_{u}^{n+1}\right|, \max \left|e_{v}^{n+1}\right|\right\} .
$$

Nas figuras 5.16 e 5.17 uma análise do comportamento da simulação é mostrada no decorrer de 0.64s. Na primeira delas, apresentamos os valores do passo temporal adaptativo. Como para este modelo, não se tem estado estacionário, o passo de tempo não cresce até ser limitado pela condição $C F L$, oscilando constantemente, devido à presença da superfície livre.

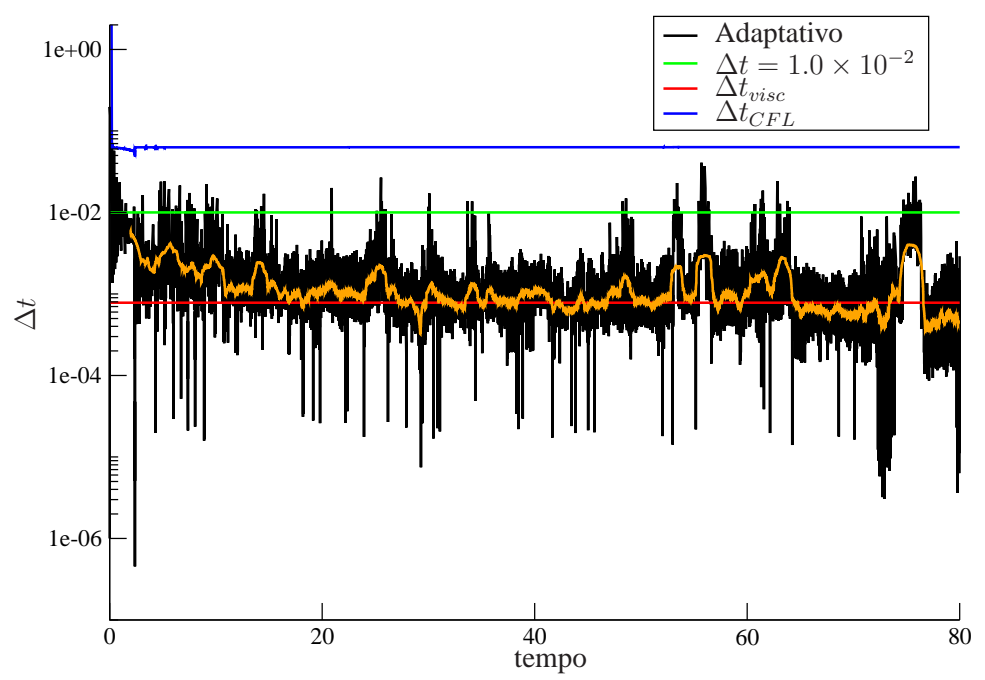

Figura 5.16: Valores do passo temporal usados na simulação do jet flow, considerando $\Delta m=0.125$. Em laranja, a curva do passo temporal adaptativo foi suavizada tomando-se a média dos 500 pontos vizinhos.

Na Figura 5.17 apresentamos uma comparação entre o valor do $\left\|\mathbf{e}^{n}\right\|$ para o passo adaptativo e os dois casos com passo fixo, $\Delta t_{\text {visc }}=7.8125 \times 10^{-4}$ e $\Delta t=1.0 \times 10^{-2}\left(F_{\text {visc }}=12.8\right)$. Como 
observado, o erro entre o passo temporal adaptativo e passo fixo $\Delta t_{\text {visc }}$ se comportam de maneira semelhante, mostrando que podemos utilizar o passo temporal adaptativo sem perda de precisão na solução.

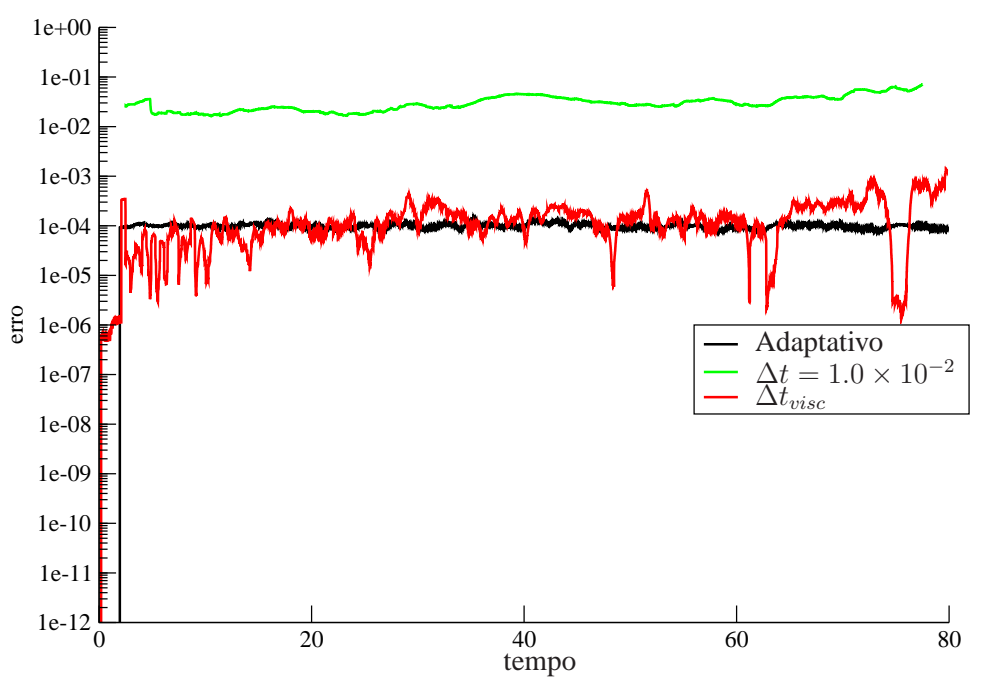

Figura 5.17: Comparação entre o valor do erro $\left\|\mathrm{e}^{n}\right\|$ para o passo temporal adaptativo e dois casos com passo fixo obtidos na simulação do jet flow. As curvas foram suavizadas tomando-se a média dos 500 pontos vizinhos.

Em termos de tempo de CPU, como é observado na Tabela 5.5, o passo temporal adaptativo se mostrou, mais uma vez, pior do que o passo fixo $\Delta t=1.0 \times 10^{-2}$, mas novamente, como é visto na Figura 5.17, seu erro $\left\|\mathbf{e}^{n}\right\|$ é menor, mostrando-se assim que o passo temporal adaptativo é mais preciso. Em relação ao $\Delta t_{\text {visc }}$ um ganho de aproximadamente 9.0 hs no tempo de processamento foi observado, e este se deve à redução de número de ciclos computacionais, ou seja, o número de sistemas lineares a serem resolvidos são reduzidos e uma solução com uma precisão fixada é produzida.

\begin{tabular}{lcc}
\hline \hline Passo de tempo & Tempo de CPU & No. Ciclos Computacionais \\
\hline \hline Adaptativo & $03: 04: 26: 04$ & 81929 \\
$\Delta t=1.0 \times 10^{-2}$ & $00: 08: 28: 04$ & 8000 \\
$\Delta t_{\text {visc }}=7.8125 \times 10^{-4}$ & $03: 13: 35: 28$ & 102400 \\
\hline \hline
\end{tabular}

Tabela 5.5: Tempo de processamento para a simulação do jet flow até $t=80.0$.

Logo, o passo temporal adaptativo pode ser utilizado em diversos problemas garantindo sempre precisão e diminuição do custo computacional. Tanto para este modelo, como os outros apresentados, consideramos, $\varepsilon=1.0 \times 10^{-4}$, e conseguimos um passo de tempo mais próximo da condição $C F L, \mathrm{o}$ que resultou num ganho em tempo de simulação. Desta forma, a fim de encontrar um passo de tempo 
ainda maior, para este modelo, tentou-se relaxar a tolerância para o cálculo da norma do erro, sendo atribuídos valores maiores que $1.0 \times 10^{-4}$ para $\varepsilon$. Em todos os casos, obteve-se o mesmo problema ao calcular a norma usando (4.18), o passo de tempo cresce muito no inicio da simulação, gerando resultados insatisfatórios.

Por fim, a Figura 5.18 mostra a solução numérica do jet flow usando o passo temporal adaptativo. Estão representados a pressão, o perfil de velocidade em $x$ e $y$, respectivamente, em $t=80.0$.
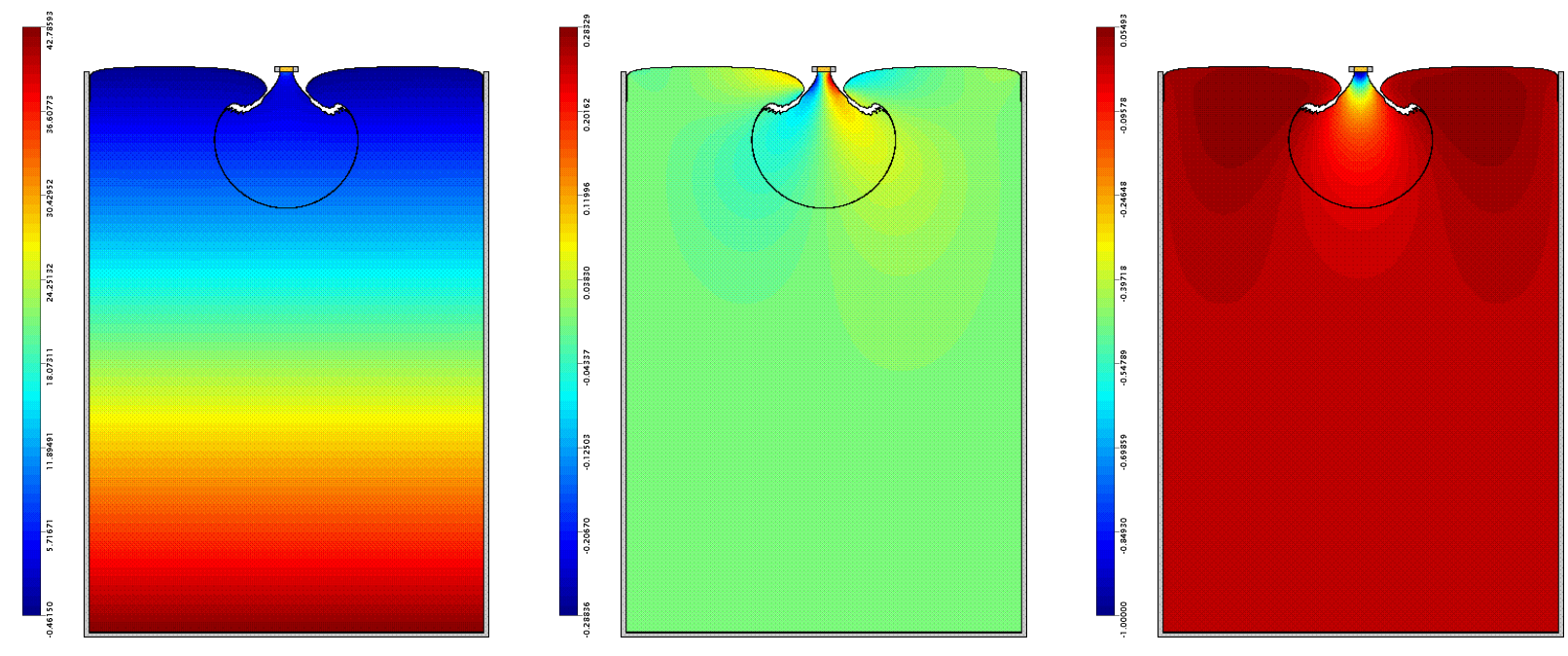

Figura 5.18: Solução numérica do jet flow $(R e=0.2)$ utilizando o passo temporal adaptativo em $t=80.0$. Na figura estão representados os resultados numéricos para pressão, perfil de velocidade em $x$ e $y$, respectivamente.

\subsection{Conclusões}

Mostramos, neste capítulo, os resultados finais das simulações feitas ao utilizar o passo temporal adaptativo incorporado à FI do GENSMAC.

Em todos os resultados apresentados, o método com passo temporal adaptativo se mostrou uma excelente forma de escolha do passo de tempo para escoamentos com superfícies livres, uma vez que este, é escolhido automaticamente, baseando-se em informações do próprio escoamento. As oscilações observadas no passo de tempo são devidas à presença da superfície livre, pois quando da movimentação da mesma, um novo problema surge. Assim, enquanto células do tipo E não se tornam células do tipo $\mathbf{S}$, o passo de tempo pode aumentar, caso contrário, uma redução é necessária. Logo, tornou-se possível eliminar, do ponto de vista prático, a inconveniência da fórmula (3.21) que contém os fatores de escala $F_{0}, F_{v i s c}$ e $F_{C F L}$ que são escolhidos sem muito critério e mantidos fixos ao longo de toda a simulação para garantir estabilidade. Desta forma, se torna possível simular, principalmente, classes de problemas em que $R e \ll 1$.

Um fator relevante em todas as simulações, é a tolerância $\varepsilon$, para o cálculo do erro. Foi adotada a sugestão presente em [KD10] de um erro relativo de $1.0 \times 10^{-4}$. Mas, ainda assim, outros 
valores foram atribuídos a $\varepsilon$ e, alguns resultados foram mostrados. Para o problema poiseuille flow, considerou-se $\varepsilon=1.0 \times 10^{-5}$, caso contrário, não seria possível captar a solução transiente nos tempos iniciais. Enquanto que, no problema jet flow, tentou-se relaxar tal valor para encontrar um passo de tempo mais próximo da condição $C F L$, mas isso resultou num aumento muito rápido no passo de tempo no início da simulação o que não possibilitou a continuação da mesma. Nos demais problemas, poderíamos, ainda exigir uma tolerância menor, mas neste caso, o número de passos de tempos rejeitados em cada ciclo se torna muito grande, e com isso, a simulação precisa ser encerrada, este fato é abordado no Passo 4-ADAP. Assim, considerar $\varepsilon=1.0 \times 10^{-4}$ ou $\varepsilon=0.01 \%$ pode ser uma margem de erro aceitável para aplicações práticas.

Em termos de precisão, para todos os problemas, conseguimos garantir que $\left\|\mathbf{e}^{n}\right\| \leq 1.0 \times$ $10^{-4}\left(\frac{1}{0.7}\right)^{1 / 3}$, o que aponta uma boa margem de segurança para decisões que necessitam ser tomadas, mas sabemos que os resultados obtidos não esgotam o assunto, uma vez que existem outros métodos com passo temporal adaptativo que poderiam ser estudados e testados no GENSMAC. Além disso, foi possível mostrar que os princípios físicos de cada problema foram conservados, tal fato foi identificado quando o estado estacionário era atingido no tempo devido. Outro ganho significativo foi em relação ao tempo de processamento e no número de ciclos computacionais. Em todos os problemas houve um ganho em tempo de CPU, chegando a aproximadamente, $95 \%$ em problemas com superfícies livres que atingiam o estado estacionário, como foi o caso do fountain flow e inchamento do extrudado. Mas mesmo quando o ganho foi menor, de aproximadamente 9 hs, no caso do jet flow, para este tipo de problema que possui um número de células semelhante a uma simulação $3 D$, o ganho foi muito significativo, indicando que em simulações $3 D$, este método também poderá ser eficiente.

Por fim, vale ressaltar que todos os problemas foram testados a baixos Reynolds, onde a busca por um passo temporal maior é justificado. Para outras classes de problemas, outro estudo seria necessário o que não faz parte deste trabalho. 


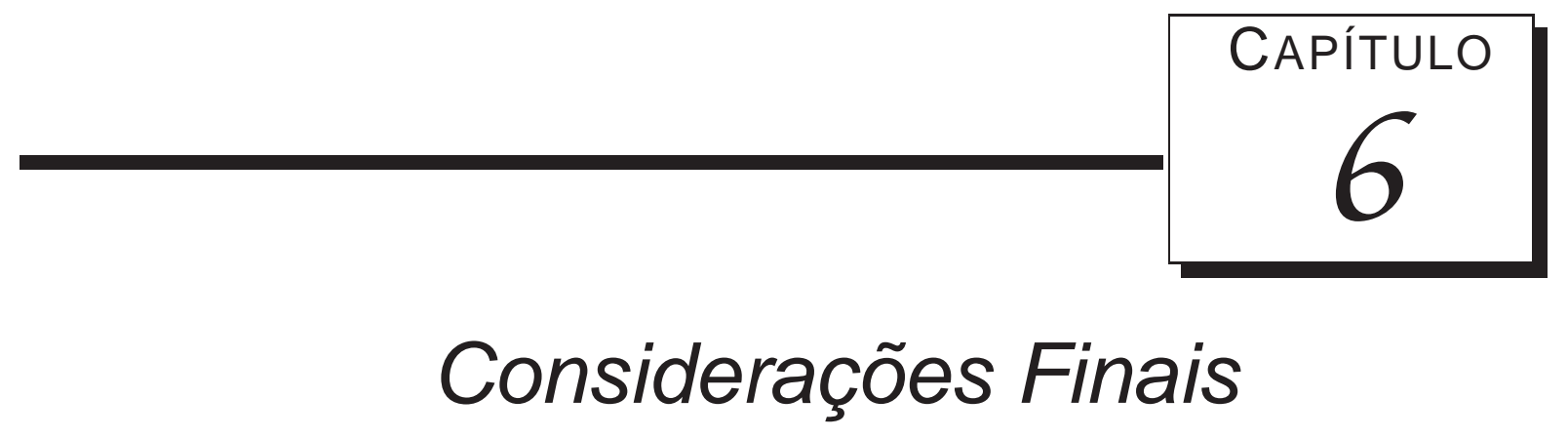

O foco deste trabalho foi a implementação do método com passo temporal adaptativo para a simulação de escoamentos com superfícies livres. Em especial, foi de interesse o caso de escoamentos viscosos, a baixos Reynolds.

Para isso, após a apresentação das equações que modelam o escoamento de um fluido newtoniano e as condições auxiliares, realizamos, no Capítulo 3, uma breve apresentação do GENSMAC como método de projeção e o algoritmo da formulação implícita, a qual se faz importante por eliminar a restrição de estabilidade parabólica no passo temporal em escoamentos com superfícies livres. Mas ainda assim, uma restrição no passo de tempo é aplicada a fim de garantir precisão nos resultados numéricos e o não aparecimento de resultados não físicos.

A partir de então, no Capítulo 4 foi proposta uma estratégia para contornar essa dificuldade. Apresentamos a formulação matemática para o método com passo temporal adaptativo que possibilitou o aumento no passo temporal em relação àquele dado pela restrição parabólica da FE do GENSMAC, principalmente em escoamentos a baixos Reynolds.

Assim, tal técnica foi testada no Capítulo 5 produzindo resultados bastante interessantes. A título de experimento para comparação dos resultados, uma versão do método numérico sempre foi testada utilizando o menor passo de tempo possível (o dado pela restrição parabólica), a fim de servir como referência.

Nesse sentido, o método com passo temporal adaptativo mostrou-se bastante eficiente, produzindo um erro relativo de $0.01 \%$ o que é uma margem de erro aceitável para aplicações práticas. Além disso, um ganho em tempo de processamento foi observado em todos os problemas, chegando, em alguns casos, na ordem de $90 \%$ em relação ao tempo de CPU gasto usando o passo de tempo da FE.

Ainda é importante salientar que os resultados obtidos, embora relativamente simples, têm sua importância ao tornarem a FI do GENSMAC ainda mais eficiente e precisa, podendo contribuir, também, 
com a FE do GENSMAC.

Portanto, a principal contribuição deste trabalho é a modificação do cálculo do passo temporal no GENSMAC, no contexto de um fluido newtoniano a baixo Reynolds, que garante precisão e baixo custo computacional.

Dessa forma, os resultados obtidos com este trabalho serão comunicados à comunidade na forma de artigos. Um resumo abordando algumas partes específicas do trabalho foi submetido ao CNMAC 2012. Possíveis temas para trabalhos futuros dizem respeito à:

- implementar o método com passo temporal adaptativo para a simulação de escoamentos tridimensionais;

- implementar o método com passo temporal adaptativo para a simulação de escoamentos viscoelásticos em duas e três dimensões;

- analisar e implementar técnicas com adaptatividade também para o espaço. 


\section{Referências Bibliográficas}

[AH70] A. Amsden and F. H. Harlow. A simplified MAC technique for incompressible fluid flow calculations. J. Comp. Physics, 6:332-335, 1970.

[AP03] M. Alves, P. Oliveira, and F. Pinho. A convergent and universally bounded interpolation scheme for the treatment of advection. Int. J. Numer. Meth. Fluids, 41:47-75, 2003.

[AR97] V. Armenio. An improved MAC method (SIMAC) for unsteady high-reynolds free surface flows. Int. J. Numer. Meth. Fluids, 24:185-214, 1997.

[BH87] B. R. Bird, R. C. Armstrong, and O. Hassager. Dynamics of polymeric liquids. John Willey \& Sons, I, 1987.

[BR01] D. L. Brown, R. Cortez, and M. L. Minion. Accurate projection methods for the incompressible Navier-Stokes equations. J. Comp. Physics, 168:464-499, 2001.

[BU03] J. Butcher. Numerical methods for ordinary differential equations. Wiley, 2003.

[CF00] A. F. Castelo, M. F. Tomé, L. M. Cesar, J. A. Cuminato, and S. Mckee. Freeflow: an integrated simulation system for three-dimensional free surface flows. Comput. Vis. Sci, 2:199-210, 2000.

[CH67] A. Chorin. A numerical method for solving incompressible viscous flow problems. $J$. Comp. Physics, 2:12-26, 1967.

[CH68] A. Chorin. Numerical solution of the Navier-Stokes. Mathematics of Computation, 2:745-762, 1968.

[CH00] A. Chorin and J. E. Marsden. A mathematical introduction to fluid mechanics. Springer, 2000.

[FL91] C. A. J. Fletcher. Computational techniques for fluid dynamics. Springer, Vol. I e II, 1991. 
[FT00] A. O. Fortuna. Técnicas computacionais para dinâmica dos fluidos: conceitos básicos e aplicações. Edusp, 2000.

[GP08] P. M. Gresho, D. F. Griffiths, and D. J. Silvester. Adaptative time-stepping for incompressible flow. Part I: Scalar advection-diffusion. SIAM J. Sci. Comput., 30:2018-2054, 2008.

[GS00A] P. M. Gresho and R. L. Sani. Incompressible flow and the finite element method: Vol. 1: Isothermal laminar flow. John Wiley, Chichester, UK, 2000.

[GS00B] P. M. Gresho and R. L. Sani. Incompressible flow and the finite element method: Vol. 2: Isothermal laminar flow. John Wiley, Chichester, UK, 2000.

[HN00] E. Hairer, S. P. Norsett, and G. Wanner. Solving ordinary differential equations I: Nonstiff problems. Computational Mathematics, Springer, Berlin, 8, 2000.

[HW65] F. H. Harlow and J. E. Welch. Numerical calculation of time-dependent viscous imcompressible flow of fluid with free surface. Physics of Fluids, 8:2182-2189, 1965.

[KD10] D. A. Kay, P. M. Gresho, D. F. Griffiths, and D. J. Silvester. Adaptative time-stepping for incompressible flow. Part II: Navier-Stokes equations. SIAM J. Sci. Comput., $32: 111-128,2010$.

[MM88] M. Mäntylä. An introduction to solid modeling. Computer Science Press, Rockville, MD, 1988.

[MF09] F. P. Martins. Desenvolvimento de um método numérico implícito para a simulação de superfícies livres. Dissertação de de Mestrado, ICMC-USP - São Carlos, 2009.

[MF97] J.P. Morris, P. J. Fox, and Y. Zhu. Modeling low reynolds number incompressible flows using SPH. Journal of Computational Physics, 136:214-226, 1997.

[OC04] C. Oishi. Análise e implementação de métodos implícitos no sistema Freeflow2D. Dissertação de Mestrado, ICMC/USP - São Carlos, 2004.

[OC06] C. Oishi, J. A. Cuminato, V. Ferreira, M. F. Tomé, A. F. Castelo, N. Mangiavacchi, and S. McKee. A stable semi-implicit method for free surface flows. J. of Applied Mech., 73:940-947, 2006.

[OC08A] C. Oishi, J. A. Cuminato, J. Y. Yuan, and S. McKee. Stability of numerical schemes on staggered grids. Numerical Linear Algebra with Applications, aceito para publicação, 2008, DOI: 10.1002/nla.597.

[OC08B] C. Oishi. Análise e implementação de métodos implícitos e de projeção para escoamentos com superfície livre. Tese de Doutorado, ICMC/USP - São Carlos, 2008. 
[OL99] J. Oliveira. Desenvolvimento de um sistema de simulacão de escoamentos de fluidos com superfícies livres bidimensionais. Dissertação de Mestrado, ICMC/USP - São Carlos, 1999.

[TM93] M. F. Tome. GENSMAC: a multiple free surface fluid flow solver. Tese de Doutorado, Department of Mathematics - University of Atrathclyde, 1993.

[TM94] M. F. Tome and S. McKee. GENSMAC: a computational marker-and-cell method for free surface flows in general domains. J. Comp. Physics, 110:171-186, 1994.

[TM99] M. F. Tome, S. McKee, L. Barratt, D. A. Jarvis, and A. J. Patrick. An experimental and numerical investigations of container filling whith viscous liquids. Int. J. Numer. Meth. Fluids, 31:1333-1353, 1999. 